\title{
Reduction of solvent effect in reverse phase gradient elution LC-ICP-MS
}

by

\author{
Patrick Allen Sullivan
}

\begin{abstract}
A thesis submitted to the graduate faculty
in partial fulfillment of the requirements for the degree of MASTER OF SCIENCE
\end{abstract}

Major: Analytical Chemistry

Program of Study Committee:

R.S. Houk, Major Professor

David Laird

Marc Porter

Iowa State University

Ames, Iowa

2006 


\section{Graduate College}

Iowa State University

This is to certify that the master's thesis of

Patrick Allen Sullivan

has met the thesis requirements of Iowa State University

Major Professor

For the Major Program 


\section{TABLE OF CONTENTS}

GENERAL INTRODUCTION

Introduction

References

SOLVENT REMOVAL AND INTERNAL STANDARDIZATION

TO CORRECT FOR SENSITIVITY CHANGES FROM

METHANOL - WATER MIXTURES IN ICP-MS

Abstract

Introduction

Experimental

Results and Discussion

Conclusion

Acknowledgement

References

Tables

Figures

SOLVENT REMOVAL AND INTERNAL STANDARDIZATION

FOR QUANTIFICATION IN LC-ICP-MS WITH GRADIENT ELUTION

Abstract

Introduction

Experimental

Results and Discussion

Conclusion

Acknowledgement

References

Tables

Figures 


\section{GENERAL INTRODUCTION}

Quantification in liquid chromatography (LC) is becoming very important as more researchers are using $\mathrm{LC}$, not as an analytical tool itself, but as a sample introduction system for other analytical instruments. The ability of LC instrumentation to quickly separate a wide variety of compounds makes it ideal for analysis of complex mixtures. ${ }^{\prime}$ For elemental speciation, LC is joined with inductively coupled plasma mass spectrometry (ICP-MS) to separate and detect metal-containing, organic compounds in complex mixtures, such as biological samples. Often, the solvent gradients required to perform complex separations will cause matrix effects within the plasma. This limits the sensitivity of the ICP-MS and the quantification methods available for use in such analyses. ${ }^{2}$

Traditionally, isotope dilution has been the method of choice for LC-ICP-MS quantification. The use of naturally abundant isotopes of a single element in quantification corrects for most of the effects that LC solvent gradients produce within the plasma. ${ }^{1}$ However, not all elements of interest in speciation studies have multiple naturally occurring isotopes; and polyatomic interferences for a given isotope can develop within the plasma, depending on the solvent matrix. This is the case for reverse phase LC separations, where increasing amounts of organic solvent are required. ${ }^{3}$ For such separations, an alternative to isotope dilution for quantification would be is needed.

To this end, a new method was developed using the Apex-Q desolvation system (ESI, Omaha, NE) to couple LC instrumentation with an ICP-MS device. The desolvation power of the system allowed greater concentrations of methanol to be introduced to the plasma prior to destabilization than with direct methanol injection into the plasma. Studies were performed, using simulated and actual linear methanol gradients, to find analyte-internal standard (AIS) pairs whose ratio remains consistent (deviations $< \pm 10 \%$ ) over methanol concentration ranges of 5\% - 35\% (simulated) and 8\% - 32\% (actual). Quadrapole (low resolution) and sector field (high resolution) ICP-MS instrumentation were utilized in these studies.

Once an AIS pair is determined, quantification studies can be performed. First, an analysis is performed by adding both elements of the AIS pair post-column while performing 
the gradient elution without sample injection. A comparison of the ratio of the measured intensities to the atomic ratio of the two standards is used to determine a correction factor that can be used to account for the matrix effects caused by the mobile phase. Then, organic and/or biological molecules containing one of the two elements in the AIS pair are injected into the LC column. A gradient method is used to vary the methanol - water mixture in the mobile phase and to separate out the compounds in a given sample. A standard solution of the second ion in the AIS pair is added continuously post-column. By comparing the ratio of the measured intensities to the atomic ratio of the eluting compound and internal standard, the concentration of the injected compound can be determined. ${ }^{2}$

\section{REFERENCES}

1. P. Rodríguez-González, J. M. Marchante-Gayón, J. I. G. Alonso, and A. Sanz-Medel, Spectrochim. Acta Part B 60,151 (2005)

2. M. Wind, H. Wechst, and W. D. Lehmann, Anal. Chem. 73, 3006 (2001)

3. R.S. Houk, Handbook of Elemental Speciation 5.7, 379 (2003) 


\title{
SOLVENT REMOVAL AND INTERNAL STANDARDIZATION TO CORRECT FOR SENSITIVITY CHANGES FROM METHANOL - WATER MIXTURES IN ICP-MS
}

\begin{abstract}
A paper to be submitted to The Journal of Analytical Atomic Spectroscopy
\end{abstract}

\author{
Patrick A. Sullivan and R. S. Houk*
}

\begin{abstract}
The groundwork for coupling gradient liquid chromatography (LC) with inductively coupled plasma mass spectrometry (ICP-MS) is developed. Using a micronebulizer (100 $\mu \mathrm{L} / \mathrm{min}$ ) and the Apex-Q desolvation system from Elemental Scientific, Inc., samples containing up to $40 \%$ methanol were introduced to the plasma with lower destabilization effects than attributed to strait sample introduction. Samples are introduced by flow injection (FI) to evaluate peak broadening. The desolvation system broadens the FI peak from 2 to 25

s. Ion signal ratios are measured in the presence of increasing methanol concentration to simulate gradient elution. Ions were found whose signal ratio remained consistent (deviations $< \pm 10 \%$ ) over a methanol concentration range of $5-35 \%$. Such deviations are similar to those found for natural isotopic pairs $\left({ }^{63} \mathrm{Cu}\right.$ and ${ }^{65} \mathrm{Cu},{ }^{69} \mathrm{Ga}$ and ${ }^{71} \mathrm{Ga},{ }^{203} \mathrm{Tl}$ and ${ }^{205} \mathrm{Tl}$ ) over the same concentration range. The analyte-internal standard pairs whose ratios remain consistent in the presence of increasing methanol concentration have the potential to be used in LC quantification by post - column standard addition.
\end{abstract}

\section{INTRODUCTION}

LC-ICP-MS is an analytical technique that has gained in popularity over the past few years. This technique utilizes both the separation efficiency of LC, and the elemental detection of ICP-MS. To date, LC-ICP-MS is most often used in elemental speciation 
studies, where metal containing biological and organic compounds are separated by LC and quantified using the ICP-MS. This allows researchers to determine the chemical species in which a given element is found. This also helps researchers determine if a given element is at desired amounts in the human body, or reaching levels of toxicity.

Elemental speciation through LC-ICP-MS has taken many forms, mostly due to the wide variety of LC separation techniques available. Depending on sample requirements, researchers can use size exclusion, for analytes of wide size distribution; ion exchange, for charged species; and normal or reverse phase, for nonpolar analytes.' For most metal containing biological compounds, ion exchange chromatography (IEC) has been shown to efficiently separate complex mixtures in reasonable amounts of time. Hintelmann used IEC to effectively separate many arsenic compounds extracted from freshwater fish. ${ }^{2}$ Similar studies performed by Roig-Navarro and Hernández show comparable separation efficiencies for arsenic, selenium, and chromium containing species in water and soil samples. ${ }^{3,4}$ Reverse phase LC has also proven its worth in the field of elemental speciation. Miller-Ihli was able to utilize reverse phase techniques in their studies of cobalamin species in vitamin B-12. Their results displayed good separation, but long acquisition times. ${ }^{5}$ Furthermore, pharmaceutical studies performed by Marshall and colleagues using reverse phase LC in conjunction with sample derivatization of carboxylic acid samples to adequately separate different iron containing species. ${ }^{6}$

The main drawback to coupling LC to ICP-MS for use in elemental speciation is most apparent when quantification is desired. By design, LC makes use of solvents or running buffers whose matrices are different enough from the stationary phase of the column to support separation. These matrices can have a profound effect on the plasma, and can effect how well elements are ionized within the plasma. If the mobile phase remains the same (isocratic) throughout a separation, the effects can be corrected by blank subtraction or internal standardization. However, most LC separations require gradients in order to effectively separate analytes. This means that the solvent or running buffer concentration is changed over the course of a separation. This poses a problem, as different solvent compositions can have varying effects on plasma conditions and ionization ability. This is best seen in reverse phase gradients, when increasing amounts of organic solvents are needed 
to facilitate separation. As more organic solvent reaches the torch, the plasma destabilizes and ion sensitivities change. This makes quantification through internal standards difficult at best, for the signal change is not the same for all elements. Wind and co-workers have shown that the signal ratio for phosphorous to sulfur, often used as an internal standard pair, increases by a factor of three in the presence of a linear methanol gradient. ${ }^{7}$

The most effective way to counter the effects of changing solvent matrices on quantification is the use of isotope dilution. In this technique, a spike is added to a sample that contains a known amount of one of the natural occurring isotopes of the ion of interest. This spike changes the isotopic ratio from that of the natural abundance. Quantification is then achieved by measuring the new ratio of the stable isotopes, and comparing them to the natural abundance. Then the concentration of the sample ion can be calculated. ${ }^{8}$ This technique works well for quantification in a gradient due to the fact that isotopes of the same element will react to matrix effects in the same manner. If the signal for one isotope is suppressed, it is proportionally suppressed for all other isotopes, and the signal ratio stays the same.

Isotope dilution is not the answer to all of the problems of gradient effects. First, not all ions of interest in speciation studies have more than one stable isotope. Arsenic for example has only one isotope at $\mathrm{m} / \mathrm{z}=75$, and is not a good candidate for isotope dilution studies. This is the same for cobalt at $\mathrm{m} / \mathrm{z}=59$. Another issue that limits isotope dilution for some elements is ion interferences. Often times, stable isotopes of more than one element will have the same mass. This limits the number of available isotopes for use in such experiments. Furthermore, increasing the organic solvent content, as in the case of reverse phase separations, often increases the amount of polyatomic interferences. These polyatomic species can interfere at $\mathrm{m} / \mathrm{z}$ where atomic interferences do not, and decrease the number of available isotopes for use with this technique.

A possible solution to the interference problems seen when using isotope dilution with organic gradients is to not use isotope dilution, but to find sets of elements whose signals change similarly with solvent composition. In studies performed by Barnes and AlAmmar, boron and beryllium were shown to act as good internal standards in aqueous matrices that exerted non-spectroscopic effects on the elements of interest. Both elements 
experienced the same signal enhancement and suppression in the presence of $\mathrm{Na}, \mathrm{K}, \mathrm{Ca} .{ }^{10}$ Further studies by this group showed similar results for 13 other elements. They surmised that such signal enhancements were a result of space charge effects within the extracted ion beam." Going a step further, $\mathrm{Hu}$ and coworkers studied ion signal enhancement and suppression resulting from organic introduction to the plasma. These studies showed that signal enhancement, and suppression, is dependent on the atomic weight and ionization energy of a given element. ${ }^{12}$

In this study, we take the investigation of ion pairs a step further by utilizing the latest developments in sample introduction. We began with a moderate flow nebulizer (100 $\mu \mathrm{L} / \mathrm{min}$ ) which allows less organic solvent into the plasma, while having about the same sensitivity as nebulizers with conventional flow rates. When adding the Apex-Q desolvation system, from Elemental Scientific, we were able to study the effects of increasing methanol concentration on ion pair signal ratios. The desolvation power of the system allowed us to increase the amount of methanol in our samples up to $40 \%$ without extinguishing the plasma. We found several analyte-internal standard (AIS) pairs whose signal ratio do not deviate greatly (deviations $< \pm 10 \%$ ) over a methanol concentration range of $5-35 \%$. For brevity, such AIS pairs are said to remain consistent in the discussion below. It is our belief that the AIS pairs whose ratios remain consistent in the presence of increasing methanol have the potential to be used in quantification during LC separations.

\section{EXPERIMENTAL}

Desolvation system. The desolvator (Figure 1) consists of a heated cyclonic spray chamber coupled to a peltier-cooled multiple pass condenser. The spray chamber can be set to 120 or $140^{\circ} \mathrm{C}$, while the condenser runs at -5 or $2^{\circ} \mathrm{C}$. Samples are introduced to the desolvator through the natural uptake of a concentric micro-nebulizer (PFA 100, ESI). The resulting aerosol is completely dried in the spray chamber and then passed through the condenser by the carrier gas. During the multiple passes through the condenser, the solvent vapor condenses and pools in the bottom of the loops. The condensed solvent is pumped to waste, while the dry sample aerosol is sent out to the plasma. The sample gas flow was set to 
$0.75 \mathrm{~L} / \mathrm{min}$, and a makeup gas rate of $0.25 \mathrm{~L} / \mathrm{min}$ was added to optimize the nebulizer efficiency.

ICP-MS Device. In this study, the desolvator was attached to an HP 4500 ICP-MS device. The desolvation system replaced the Babington nebulizer and double pass Scott spray chamber that are commonly found on the instrument. Conditions were optimized daily to maximize $\mathrm{M}^{+}$signal in $1 \%$ nitric acid over the full mass range. Typical operating conditions are shown in Table 1.

Samples. Methanol concentration was varied in order to simulate a solvent gradient ranging from $5 \%$ to $35 \%$ methanol in water. Stock solutions were used to make intermediate solutions that were $4 \mathrm{ppm} \mathrm{As}, \mathrm{Ba}, \mathrm{Cd}, \mathrm{Ce}, \mathrm{Co}, \mathrm{Cu}, \mathrm{In}, \mathrm{La}, \mathrm{Mn}, \mathrm{Ni}, \mathrm{Pb}, \mathrm{Sc}, \mathrm{Se}, \mathrm{Th}, \mathrm{Ti}, \mathrm{Tl}, \mathrm{U}$, and $V$. In seven prepared samples, the analyte and nitric acid concentrations were kept constant while the concentration of methanol increased by $5 \%$ for each. Typically, element concentrations of $10 \mathrm{ppb}$ were used, although some elements needed concentrations up to $120 \mathrm{ppb}$ due to low isotopic abundance or high blanks. Nitric acid concentration was kept at $3 \%$ for all working samples, blanks, and rinses. Distilled deionized water $\left(18 \mathrm{M} \Omega \mathrm{cm}^{-1}\right.$, Milli-Q purification system, Millipore) was used in all sample preparation.

Procedures. Ten ppb samples of $\mathrm{Ni}$ in $1 \%-3 \%$ nitric acid were used to evaluate the band broadening effects of sample transport through the desolvator. The ICP-MS was operated in time resolved analysis mode. A blank solution of $3 \%$ nitric acid was introduced to the desolvation system for 2 min prior to analysis. After $1 \mathrm{~min}$ of analysis, a $2 \mathrm{~s}$ sample plug was sent to the system followed by 2 min of blank uptake. Additional $2 \mathrm{~s}$ plugs were sent into the system every 2 min to test reproducibility.

The gradient simulation trials consisted of fourteen samples (seven solutions of increasing methanol concentration and the corresponding blanks). Each sample was nebulized for $2 \mathrm{~min}$ followed by $30 \mathrm{~s}$ to $2 \mathrm{~min}$ of analysis, depending on the number of ions of interest or the number of spectra averaged. Between each sample, a rinse solution was drawn into the desolvator for an additional $2 \mathrm{~min}$. This was done to insure that methanol did not build up within the system, and that the amount of methanol reaching the plasma was representative of a given sample. The ion signals obtained were first blank subtracted. Then, 
signal ratios were calculated in order to find ion pairs whose ratio remained consistent throughout the full range of solvent composition.

\section{RESULTS AND DISCUSSION}

Desolvator Performance. When using the desolvator in conjunction with ICP-MS one observes many positive, and a few negative, effects on the performance of the ICP-MS device. With the addition of the desolvation system, signal intensities for most metal ions doubled while the solution uptake was half the value typically used by the Babington nebulizer. The use of a PFA nebulizer increased the signal stability and lowered the noise level of a given sample. Additionally, the solvent removal provided by the system decreased oxide abundance to as low as $0.2 \%$ for $\mathrm{CeO}^{+}$and increased the amount of methanol that could be introduced to the nebulizer.

Increasing the amount of methanol entering the desolvator does change the sensitivity, as discussed below. However, the enhanced signal and lower noise provided by the desolvator helps to counter some of the undesirable effects of introducing organic solvents to the plasma. As Table 2 shows, sub ppb detection limits were observed for all elements at all methanol concentrations. This is common for the HP 4500 when no methanol is sent to the plasma. For some elements ( $\mathrm{Co}$ and $\mathrm{U}$ ) detection limits in the sub ppt range are observed. This is a prime example of how the low background noise and enhanced signal provided by the desolvation system improves ICP-MS performance even when methanol is present in the plasma. Additionally the detection limits obtained for the elements covered in this study remain fairly stable over a wide range of methanol concentrations. The slight variance observed is most likely attributed to imperfections in sample preparation than to variations in instrumental conditions.

Band Broadening. To evaluate band broadening, a two-second sample plug was injected into the desolvator. Figure 2 shows the results obtained from three two-second sample plugs introduced to the system at two minute intervals. Each plug resulted in a sample peak lasting approximately 25 seconds. Multiple trials showed that increasing the amount of nitric acid in solution, from $1 \%$ to $3 \%$, decreased the total time of the sample peak 
from 40 seconds down to the 25 second peaks shown in Figure 2. Thus, much of the band broadening takes place while the sample is still in solution. Some broadening does still occur during the transport through the desolvator to the torch, but not enough to greatly affect the efficiency of most LC separations.

\section{Effects of Methanol Concentration on Signal and Signal Ratios: $1^{\text {st }}$ Row}

Transition Elements. As stated above, the sensitivity still changes as methanol content increases. Figure 3 illustrates this effect on the signal intensities of $\mathrm{Mn}, \mathrm{Co}, \mathrm{Ni}$ and $\mathrm{Cu}$ ions in solutions of increasing methanol concentration. As the amount of methanol is increased, the ion signals go through a series of enhancements and suppressions. Similar signal enhancements were previously reported by $\mathrm{Hu}$ by aspirating solutions up to $7 \%$ methanol into the plasma. ${ }^{12}$ The fact that the signal enhancement in our studies is taking place at much higher concentrations (20\% methanol) suggests that although some methanol is making it to the torch, the amount of methanol is greatly reduced from that of the solution being aspirated.

In the Figure 4, the signal ratio was normalized to show how the signal ratio changes with respect to the initial methanol composition (5\%). In general, we were looking for ion pairs that exhibit less than a $10 \%$ ratio deviation over the range of methanol concentrations. Ions in such pairs may be used as internal standards, added post column, to quantify their partner ions in actual LC separations. In Figure $4 \mathrm{a}$, the largest deviation for the ${ }^{55} \mathrm{Mn} /{ }^{59} \mathrm{Co}$ ratio was $7 \%$. Figure $4 \mathrm{~b}$ shows an $8.1 \%$ maximum deviation for ${ }^{60} \mathrm{Ni} /{ }^{59} \mathrm{Co}$, while in fig $4 \mathrm{c}$, ${ }^{65} \mathrm{Cu} /{ }^{59} \mathrm{Co}$ has a maximum deviation of $6 \%$. In comparison, the normalized ratio for two isotopes of the same element (Figure $4 d,{ }^{63} \mathrm{Cu} /{ }^{65} \mathrm{Cu}$ ) saw deviations between $0.1 \%$ and $5 \%$.

\section{Effects of Methanol Concentration on Signal and Signal Ratios: Heavy}

Elements. Figure 5 shows the data obtained from 5\% - 35\% methanol samples that contained $\mathrm{Tl}, \mathrm{Pb}, \mathrm{Th}$, and $\mathrm{U} . \quad{ }^{203} \mathrm{Tl} /{ }^{208} \mathrm{~Pb}$ shows the best consistency with its largest deviation only $4.7 \%$ (Figure $5 \mathrm{a}$ ). In Figure $5 \mathrm{c}$ the largest deviation for ${ }^{238} \mathrm{U} /{ }^{208} \mathrm{~Pb}$ is $10 \%$. Figures $5 \mathrm{~b}$ and $5 \mathrm{~d}$ show a maximum deviation of $8 \%$ and $10 \%$ for ${ }^{232} \mathrm{Th} /{ }^{208} \mathrm{~Pb}$ and ${ }^{232} \mathrm{Th} /{ }^{238} \mathrm{U}$ respectively. It is important to note the change in the horizontal axis for these two plots. When methanol concentrations above $35 \%$ are passed through the Apex, plasma conditions began to destabilize. This leads to a decrease in ion signal which is most predominate in 
larger mass elements. For Th, the loss in sensitivity is not proportional to the sensitivity loss of both $\mathrm{Pb}$ and $\mathrm{U}$. As a result, the ratio stability degrades, and deviations over $20 \%$ are observed. In comparison, the normalized ratio for two isotopes of the same element (Figure $5 e,{ }^{205} \mathrm{Tl} /{ }^{203} \mathrm{TI}$ ) saw deviations between $0.1 \%$ and $4 \%$.

\section{Effects of Methanol Concentration on Signal and Signal Ratios: Arsenic.}

Although most elements form good ion pairs with elements of similar atomic weight, the case is not true for all elements in this study. A good example of this issue is As. As shown in Figure 6, As does not obtain consistent signal ratios with $\mathrm{Zn}$ or Se over the methanol range studied. In all As cases, deviations over $20 \%$ were observed. In Figures $6 \mathrm{c}$ and $6 \mathrm{~d}$, deviations over $60 \%$ were observed. This ratio fluctuation is mainly due to the ability of As to undergo signal enhancement significantly higher than most elements in a methanol enriched plasma. In Figures $6 \mathrm{c}$ and $6 \mathrm{~d}$, the As signal is enhanced far more than the Se signal, resulting in the large deviations at methanol concentrations over 15\%. Further studies show an inconsistency of As signal ratios obtained over time. Figures $6 \mathrm{a}$ and $6 \mathrm{~b}$ were obtained using the same sample sets. The results in Figure $6 \mathrm{~b}$ were obtained two hours after those in Figure 6a. Within that time the shape of the ratio stability graph has changed. In particular, the signal ratio at $15 \%$ and $20 \%$ methanol is greatly different after two hours time. This may be attributed to how well metal ions are able to stay in methanol solutions, but it is important to note that such changes over time were not as apparent in $\mathrm{Ni} / \mathrm{Co}$ or $\mathrm{Tl} / \mathrm{Pb}$ measurements. Signal ratio changes can also be seen when comparing Figure $6 \mathrm{c}$ with $6 \mathrm{~d}$.

A chart of all the ions that that were found in this study to have consistent signal ratios, and the AIS pairs that may be used for quantification, is shown in Table 3. The first column lists ions that are of interest in most LC separations. The good internal standard column shows ions that can be used as internal standards over most or all of the methanol range studied. The possible internal standard column lists ions whose ratios with the ion of interest are consistent (deviations less than 10\%) at most, but not all, concentrations. The largest deviation for such pairs is usually between $10 \%$ and $20 \%$, but some pairs show single point deviations greater than $20 \%$. The solution containing the larger deviations falls in the middle of the range for these ions. The differences observed could again be caused by 
imperfections in sample preparation, but in some cases, interferences and high backgrounds are to blame.

\section{Effects of Methanol Concentration on $\mathbf{M}^{+}$Signal for Metalloproteins. Once ion} pairs were found whose ratios were fairly consistent through the methanol range being studied, it was important to see if these minor deviations would remain true if one of the metal ions was attached to biological molecules. The best example of this came from studies of standard vitamin B-12 solutions. Vitamin B-12 is a good source for obtaining cobalt, and is often used as a dietary supplement to help improve heart and circulatory health. B-12 is ideal for this study due to the low background signal for cobalt ions. This was not true for samples of carbonic anhydrase and albumins in human blood serum. In both cases, we were looking at copper ions in the sample (good AIS pairs with $\mathrm{Ni}, \mathrm{Co}$, and $\mathrm{Mn}$ ).

Figure 7 shows the results obtained for these studies. As Figures $7 \mathrm{a}$ and $7 \mathrm{~b}$ show, the use of nickel and copper as internal standards for Co is still possible when Co is attached to a large biological compound such as cyanocobalamin. Equal concentrations of nickel, copper, and vitamin B-12 (10 ppb) were used to obtain the results shown. In Figure $7 \mathrm{a}$, the signal ratio remains consistent for the nickel and cobalt $\mathrm{m} / \mathrm{z}$ used. The largest variation in ${ }^{59} \mathrm{Co} /{ }^{60} \mathrm{Ni}$ ratio was $7.5 \%$. With the exception of the $20 \%$ methanol solution, the ${ }^{59} \mathrm{Co} /{ }^{63} \mathrm{Cu}$ ratio also remained within the limits of consistency (Figure $7 \mathrm{~b}$ ). The deviation at $20 \%$ methanol may be related to sample contamination, rather than signal suppression.

Figures $7 \mathrm{c}$ and $7 \mathrm{~d}$ highlight the issue that arises when studying $\mathrm{Cu}$ in organic samples such as proteins. Although cobalt was found to be a good AIS pair with copper in salt standards, the results obtained for carbonic anhydrase (Figure 7c) and albumins in human blood serum (Figure 7d) are fairly inconsistent over the methanol concentrations used. The largest deviations noticed were $23 \%$ for carbonic anhydrase and $40 \%$ for the albumins in human blood serum. These changes are mainly attributed to polyatomic interferences for

${ }^{63} \mathrm{Cu}$ that are present in the organic enriched plasma, and the low concentrations of $\mathrm{Cu}$ in the two samples used $(\leq 0.5 \mathrm{ppb})$.

\section{CONCLUSIONS}


The groundwork for coupling gradient LC with ICP-MS is developed. By utilizing the desolvation power of the system, samples containing up to $40 \%$ methanol were introduced to the plasma with lower destabilization effects than attributed to straight sample introduction. Upon evaluating the effect of the desolvator on sample transport, a tenfold increase of peak width is observed for samples passing through the desolvator to the plasma. Although most of the band broadening takes place while the sample is still in solution, some broadening does still occur during the transport through the desolvator to the torch. This broadening is not enough to greatly affect the efficiency of most LC separations used for speciation. Ion pair signal ratios were measured in the presence of varying concentrations of methanol to simulate gradient elution. Although ion sensitivity fluctuates over the methanol range studied, several ion pairs were found whose signal ratio remained consistent (deviations $< \pm 10 \%$ ) over that range. Such deviations are similar to those found for natural isotopic pairs over the same concentration range. The ion pairs whose ratios do not change greatly in the presence of increasing methanol have the potential to be used as internal standards during LC separations, as indicated by ongoing work in this lab.

\section{ACKNOWLEDGEMENTS}

This study is supported by Ames Laboratory US Department of Energy, the Chemical and Biological Sciences Program, Office of Basic Energy Science, and the ISU Chemistry Department. The Apex-Q desolvation system is on loan from Elemental Scientific Inc. in Omaha, Nebraska. Dan Wiederin of ESI offered much assistance in the set up and development of techniques involving the Apex-Q. Hewlett Packard donated the HP 4500 ICP-MS.

\section{REFERENCES}

1. B. Michalke, Trends in Anal. Chem. 21, 142 (2002)

2. J. Zheng and H. Hintelmann, J. Anal. Atomic Spectrom. Web (2003)

3. Y. Martínez-Bravo, A. F. Roig-Navarro, F. J. López, and F. Hernández, J. Chrom. A 926, 
$256(2001)$

4. L. O. Iserte, A. F. Roig-Navarro, and F. Hernández, Anal. Chimica Acta 527, 97 (2004)

5. E. G. Yanes and N. J. Miller-Ihli, Spectrochim. Acta Part B 59, 891 (2004)

6. P.S. Marshall, B. Leavens, O. Heudi, C. Ramirez-Molina, J. Chrom. A 1056, 3 (2004)

7. M. Wind, H. Wechst, and W. D. Lehmann, Anal. Chem. 73, 3006 (2001)

8. P. Rodríguez-González, J. M. Marchante-Gayón, J. I. G. Alonso, and A. Sanz-Medel, Spectrochim. Acta Part B 60,151 (2005)

9. R.S. Houk, Handbook of Elemental Speciation 5.7, 379 (2003)

10. A. S. Al-Ammar, E. Reitznerová, and R. M. Barnes, Spectrochim. Acta Part B 54, 1813 (1999)

11. A. S. Al-Ammar, R. K. Gupta, and R. M. Barnes, Spectrochim. Acta Part B 54, 1849 (1999)

12. Z. Hu, S. Hu, S. Gao, Y. Liu, and S. Lin, Spectrochim. Acta Part B 59, 1463 (2004) 
Table 1. ICP-MS operating parameters.

Rf power

Outer gas flow rate

Carrier gas flow rate

Makeup gas flow rate

Sample uptake rate

Sampling depth

Points per mass

Acquisition time per mass

Acquisition time per sample
$1200 \mathrm{~W}$

$16 \mathrm{~L} / \mathrm{min}$

$0.75 \mathrm{~L} / \mathrm{min}$

$0.25 \mathrm{~L} / \mathrm{min}$

$100 \mu \mathrm{L} / \mathrm{min}$

$7.00 \mathrm{~mm}$

3

$0.3 \mathrm{~s}$

$30-120 \mathrm{~s}$ 
Table 2. Detection limit (ppb).

\begin{tabular}{lrrrr}
\hline $\begin{array}{c}\text { Metal } \\
\text { Ion }\end{array}$ & $\begin{array}{c}5 \% \\
\text { Methanol }\end{array}$ & $\begin{array}{c}15 \% \\
\text { Methanol }\end{array}$ & $\begin{array}{c}25 \% \\
\text { Methanol }\end{array}$ & $\begin{array}{c}35 \% \\
\text { Methanol }\end{array}$ \\
$47 \mathrm{Ti}$ & 0.02 & 0.05 & 0.04 & 0.1 \\
$55 \mathrm{Mn}$ & 0.01 & 0.03 & 0.04 & 0.03 \\
$59 \mathrm{Co}$ & 0.0005 & 0.001 & 0.003 & 0.002 \\
$60 \mathrm{Ni}$ & 0.006 & 0.02 & 0.09 & 0.05 \\
$63 \mathrm{Cu}$ & 0.02 & 0.05 & 0.02 & 0.04 \\
$65 \mathrm{Cu}$ & 0.02 & 0.06 & 0.03 & 0.05 \\
$71 \mathrm{Ga}$ & 0.002 & 0.008 & 0.02 & 0.02 \\
$75 \mathrm{AS}$ & 0.01 & 0.09 & 0.05 & 0.09 \\
$111 \mathrm{Cd}$ & 0.03 & 0.03 & 0.04 & 0.03 \\
$115 \mathrm{In}$ & 0.001 & 0.002 & 0.02 & 0.007 \\
$118 \mathrm{Sn}$ & 0.01 & 0.007 & 0.02 & 0.04 \\
$137 \mathrm{Ba}$ & 0.002 & 0.02 & 0.03 & 0.06 \\
$139 \mathrm{La}$ & 0.05 & 0.01 & 0.007 & 0.007 \\
$140 \mathrm{Ce}$ & 0.03 & 0.002 & 0.003 & 0.004 \\
$203 \mathrm{TI}$ & 0.02 & 0.002 & 0.007 & 0.02 \\
$205 \mathrm{Tl}$ & 0.03 & 0.001 & 0.003 & 0.006 \\
$208 \mathrm{~Pb}$ & 0.08 & 0.09 & 0.01 & 0.07 \\
$232 \mathrm{Th}$ & 0.02 & 0.001 & 0.003 & 0.008 \\
$238 \mathrm{U}$ & 0.001 & 0.0008 & 0.002 & 0.003 \\
\hline
\end{tabular}


Table 3. Ions of interest in LC studies, and the ions that can be used as their internal standards.

\begin{tabular}{|c|c|c|}
\hline Ion of Interest & Good Internal Standard & Possible Internal Standard \\
\hline${ }^{47} \mathrm{Ti}$ & ${ }^{45} \mathrm{Sc}$ & ${ }^{51} \mathrm{~V},{ }^{55} \mathrm{Mn},{ }^{59} \mathrm{Co},{ }^{60} \mathrm{Ni}$ \\
\hline${ }^{51} \mathrm{~V}$ & ${ }^{137} \mathrm{Ba},{ }^{139} \mathrm{La},{ }^{140} \mathrm{Ce}$ & ${ }^{47} \mathrm{Ti},{ }^{59} \mathrm{Co},{ }^{60} \mathrm{Ni}$ \\
\hline${ }^{55} \mathrm{Mn}$ & ${ }^{59} \mathrm{Co},{ }^{60} \mathrm{Ni},{ }^{63} \mathrm{Cu},{ }^{65} \mathrm{Cu}$ & ${ }^{45} \mathrm{Sc},{ }^{47} \mathrm{Ti},{ }^{137} \mathrm{Ba},{ }^{139} \mathrm{La},{ }^{140} \mathrm{Ce}$ \\
\hline${ }^{59} \mathrm{Co}$ & ${ }^{55} \mathrm{Mn},{ }^{50} \mathrm{Ni},{ }^{63} \mathrm{Cu},{ }^{65} \mathrm{Cu}$ & ${ }^{51} \mathrm{~V},{ }^{45} \mathrm{Sc},{ }^{47} \mathrm{Ti},{ }^{137} \mathrm{Ba},{ }^{139} \mathrm{La},{ }^{140} \mathrm{Ce}$ \\
\hline${ }^{60} \mathrm{Ni}$ & ${ }^{55} \mathrm{Mn},{ }^{59} \mathrm{Co},{ }^{63} \mathrm{Cu},{ }^{65} \mathrm{Cu}$ & ${ }^{51} \mathrm{~V},{ }^{137} \mathrm{Ba},{ }^{139} \mathrm{La},{ }^{140} \mathrm{Ce}$ \\
\hline${ }^{63} \mathrm{Cu},{ }^{65} \mathrm{Cu}$ & ${ }^{55} \mathrm{Mn},{ }^{59} \mathrm{Co},{ }^{60} \mathrm{Ni}$ & ${ }^{137} \mathrm{Ba},{ }^{139} \mathrm{La},{ }^{140} \mathrm{Ce}$ \\
\hline${ }^{75} \mathrm{As}$ & & ${ }^{66} \mathrm{Zn},{ }^{7} \mathrm{Se},{ }^{82} \mathrm{Se}$ \\
\hline${ }^{118} \mathrm{Sn}$ & ${ }^{137} \mathrm{Ba},{ }^{139} \mathrm{La},{ }^{140} \mathrm{Ce}$ & ${ }^{111} \mathrm{Cd} \cdot{ }^{115} \mathrm{In}$ \\
\hline${ }^{208} \mathrm{~Pb}$ & ${ }^{203} \mathrm{Tl},{ }^{205} \mathrm{Tl},{ }^{232} \mathrm{Tlh},{ }^{238} \mathrm{U}$ & \\
\hline${ }^{238} \mathrm{U}$ & ${ }^{232} \mathrm{Th},{ }^{208} \mathrm{~Pb}$ & ${ }^{203} \mathrm{Tl},{ }^{205} \mathrm{Tl}$ \\
\hline
\end{tabular}




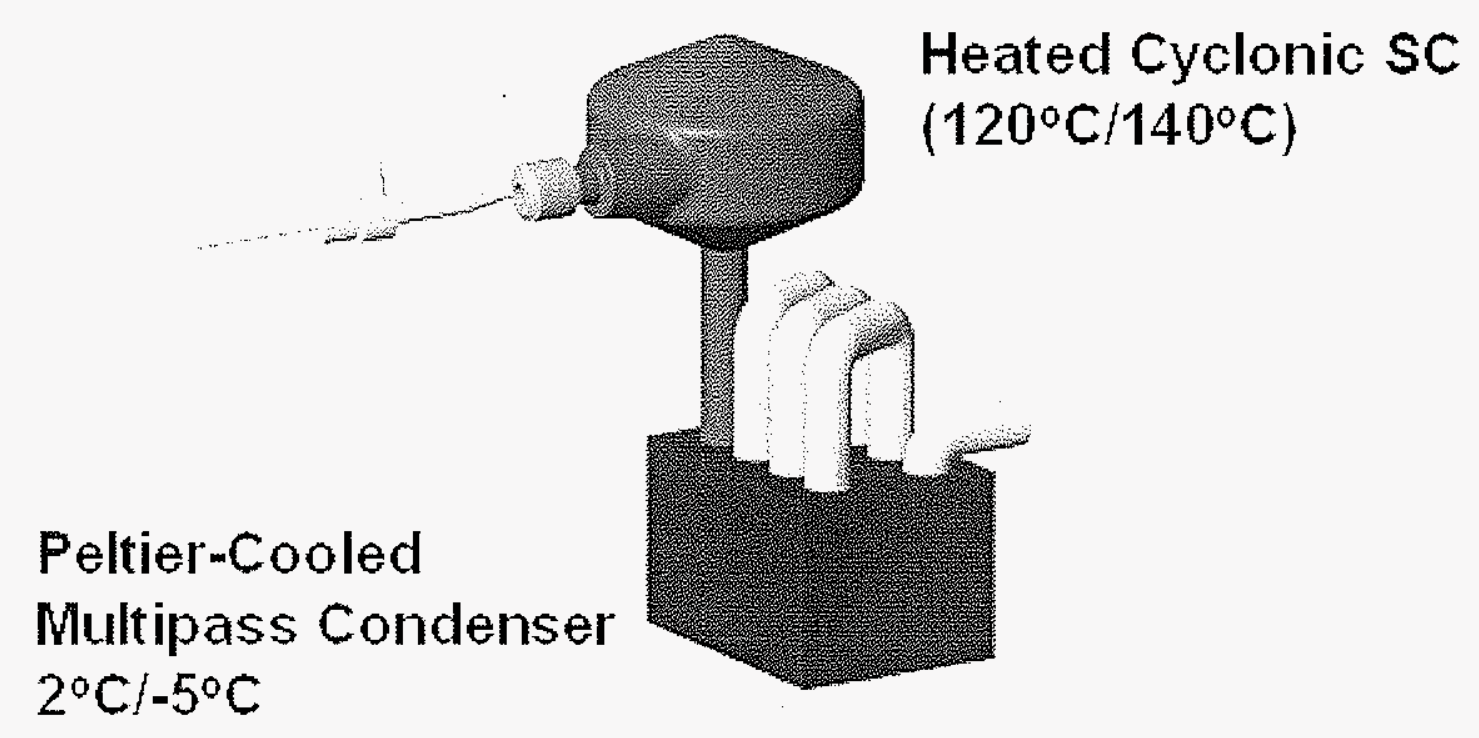

\section{Total Internal Volume $180 \mathrm{ml}$}

Figure 1. Block Diagram of the Apex-Q Desolvation System. 


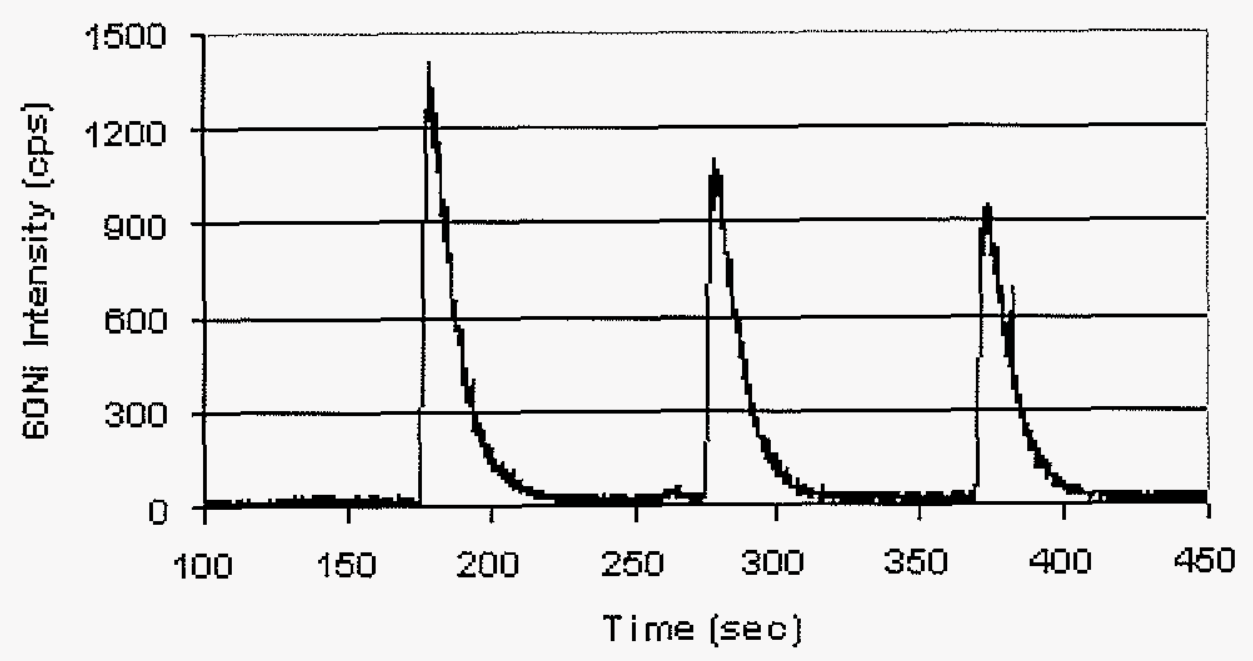

Figure 2. Time resolved spectrum of two second $10 \mathrm{ppb}{ }^{60} \mathrm{Ni}$ sample plugs in $3 \%$ nitric acid. 


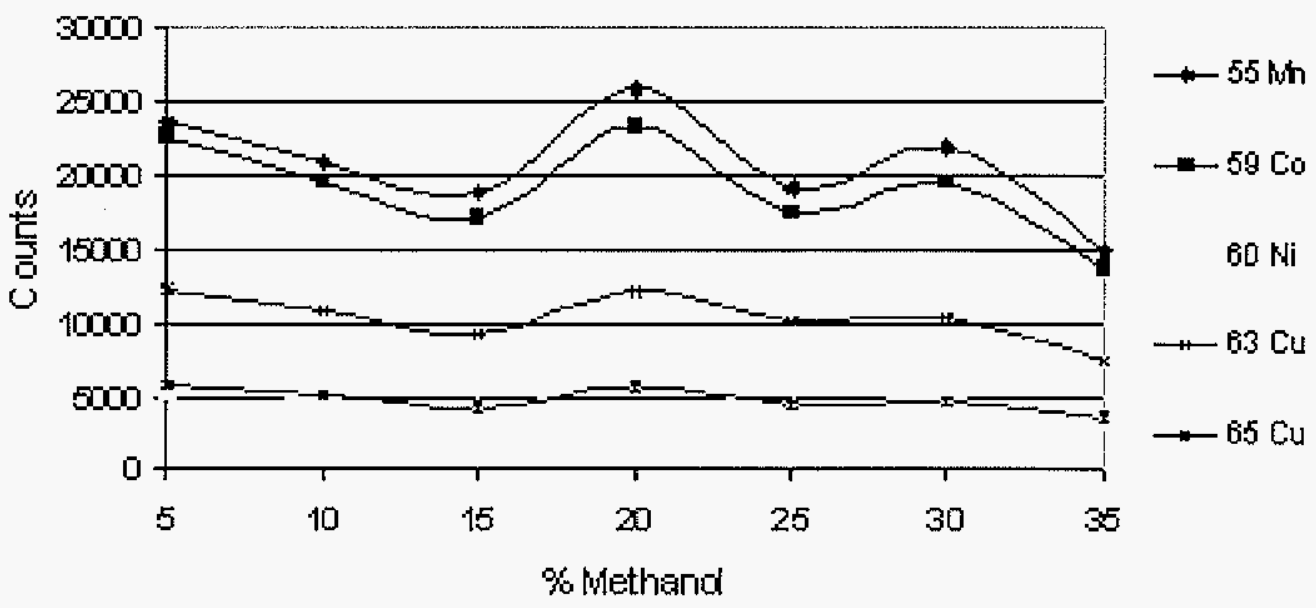

Figure 3. Fluctuations in metal ion intensity vs. methanol concentration. 
(a)

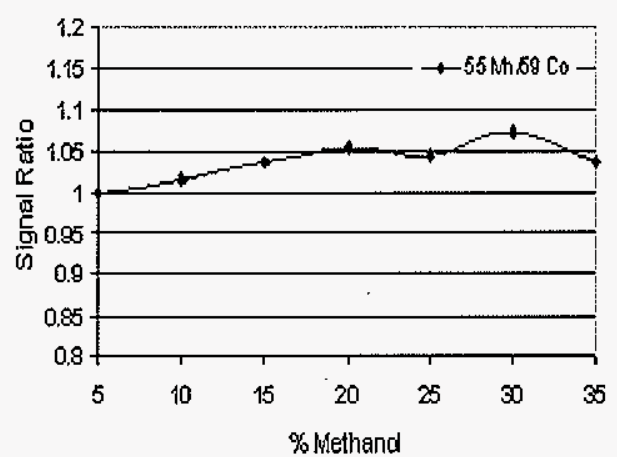

(c)

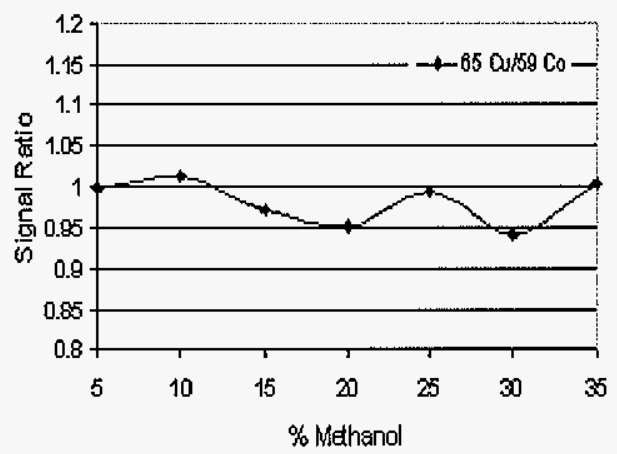

(b)

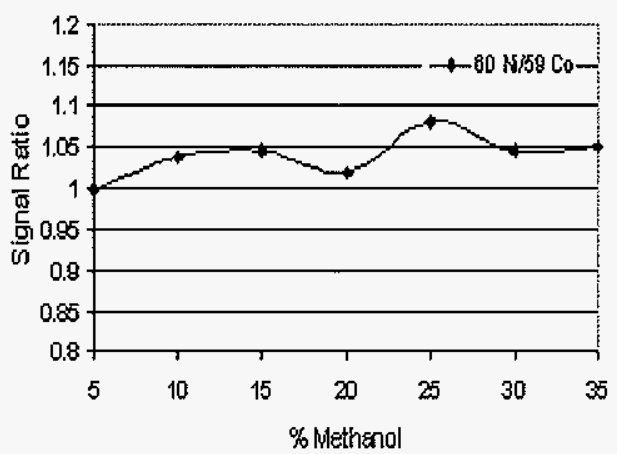

(d)

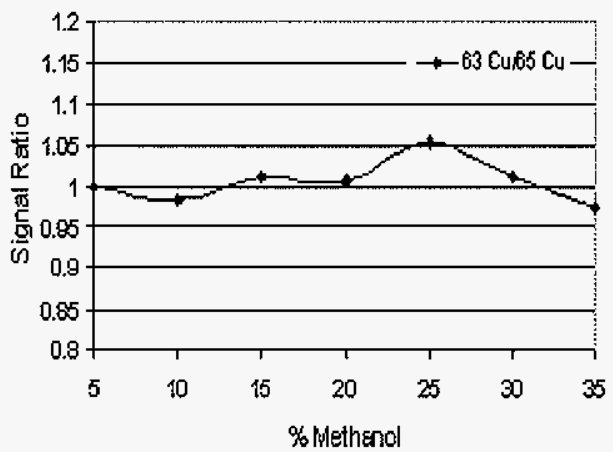

Figure 4. Ion ratios for ${ }^{55} \mathrm{Mn} /{ }^{59} \mathrm{Co}(\mathrm{a}),{ }^{60} \mathrm{Ni} /{ }^{59} \mathrm{Co}(\mathrm{b}),{ }^{65} \mathrm{Cu} /{ }^{59} \mathrm{Co}(\mathrm{c})$, and ${ }^{63} \mathrm{Cu} /{ }^{65} \mathrm{Cu}$ (e) over a methanol concentration range of 5\%-35\%. Ion ratios are normalized to show deviation from ratio in $5 \%$ methanol. 
(a)

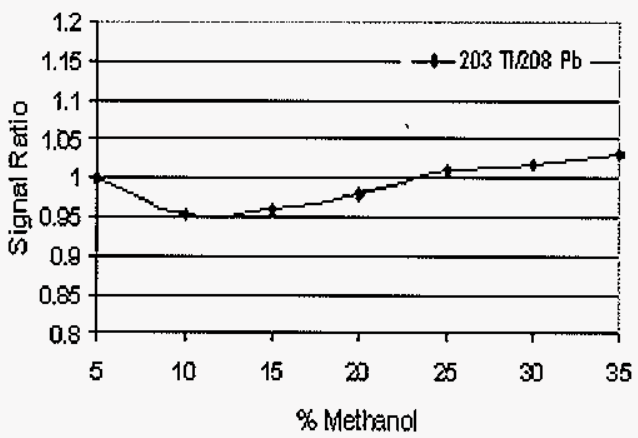

(c)

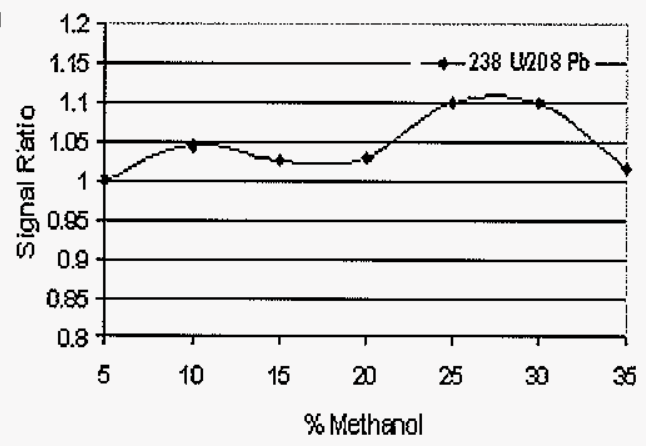

(b)

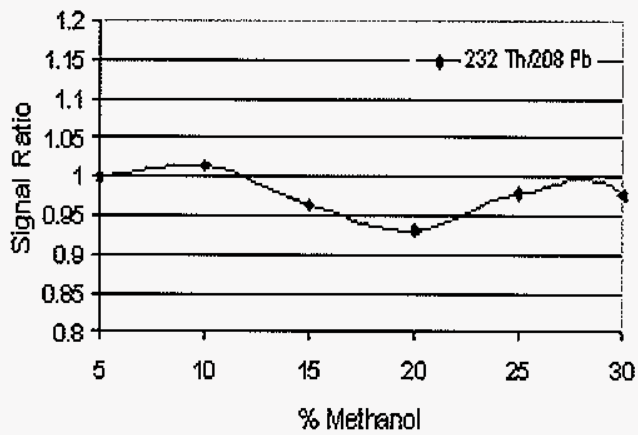

(d)

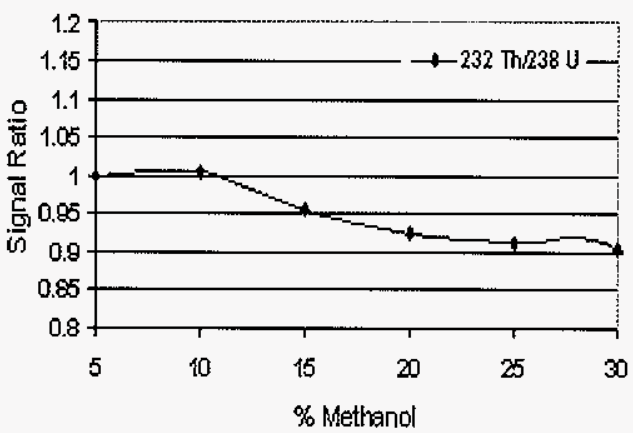

(e)

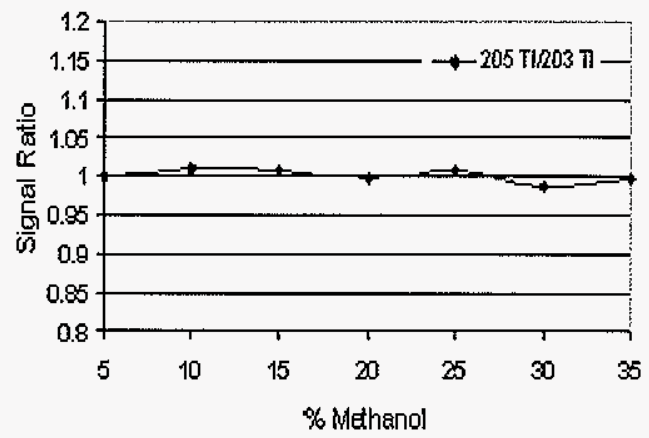

Figure 5. Ion ratios for ${ }^{203} \mathrm{Tl} /{ }^{208} \mathrm{~Pb}(\mathrm{a}),{ }^{232} \mathrm{Th} /{ }^{208} \mathrm{~Pb}(\mathrm{~b}),{ }^{238} \mathrm{U} /{ }^{208} \mathrm{~Pb}(\mathrm{c}),{ }^{232} \mathrm{Th} /{ }^{238} \mathrm{U}$ (d), and ${ }^{205} \mathrm{Tl} /{ }^{203} \mathrm{Tl}$ (e) in varying ranges of methanol concentrations. Ion ratios are normalized to show deviation from ratio in $5 \%$ methanol. 
(a)

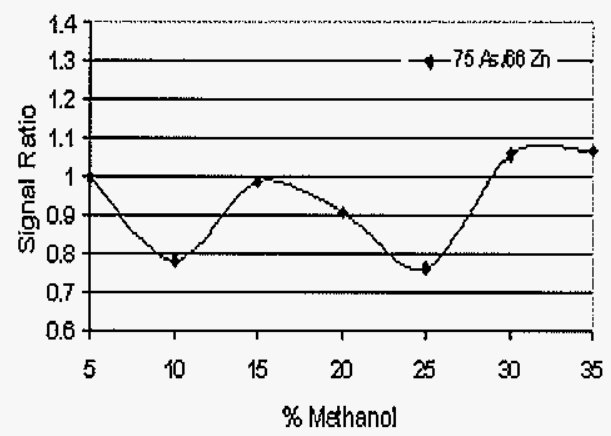

(c)

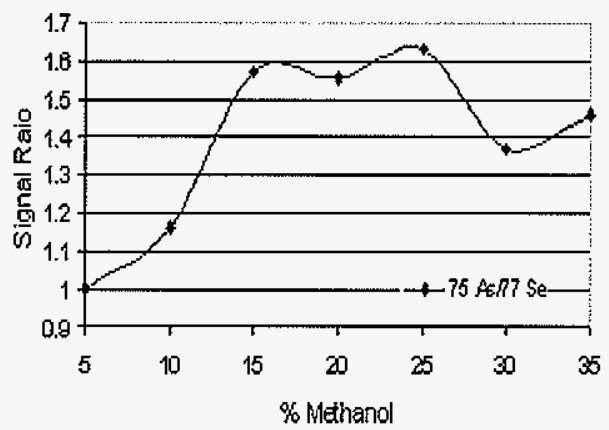

(b)

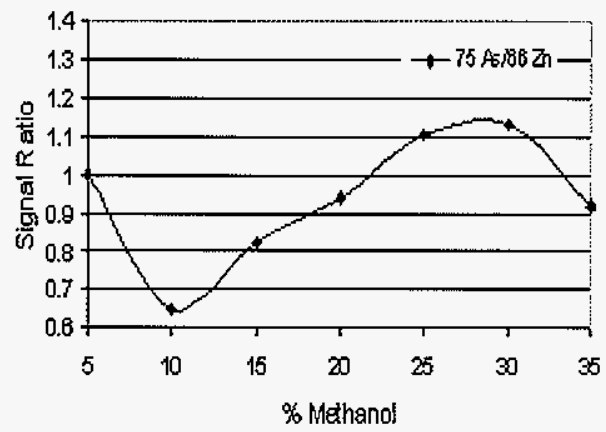

(d)

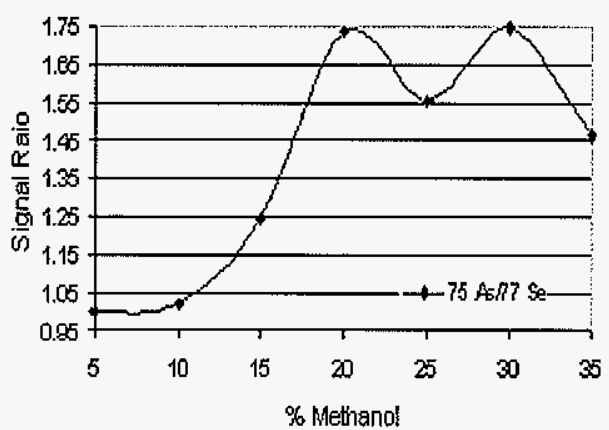

Figure 6. Ion ratios for ${ }^{75} \mathrm{As} /{ }^{66} \mathrm{Zn}$ (a) and (b), and ${ }^{75} \mathrm{As} /{ }^{77} \mathrm{Se}(\mathrm{c})$ and (d) over a methanol concentration range of $5 \%-35 \%$. Ion ratios are normalized to show deviation from ratio in $5 \%$ methanol. Comparison of (a) with (b) and (c) with (d) shows the inconsistency of As ratios in sample sets run after only two hours time. 

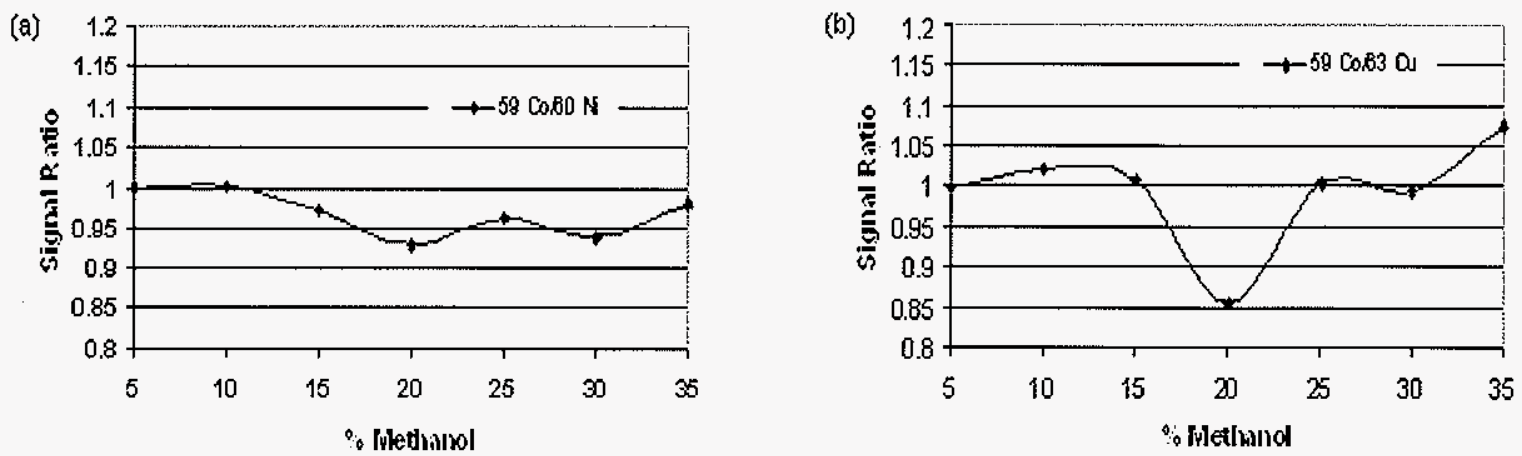

(c)

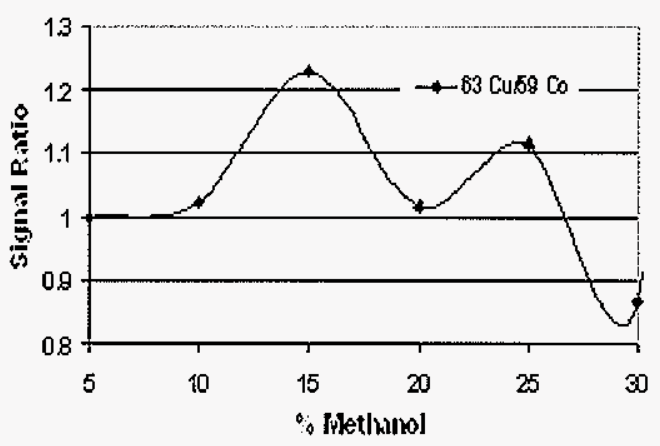

(d)

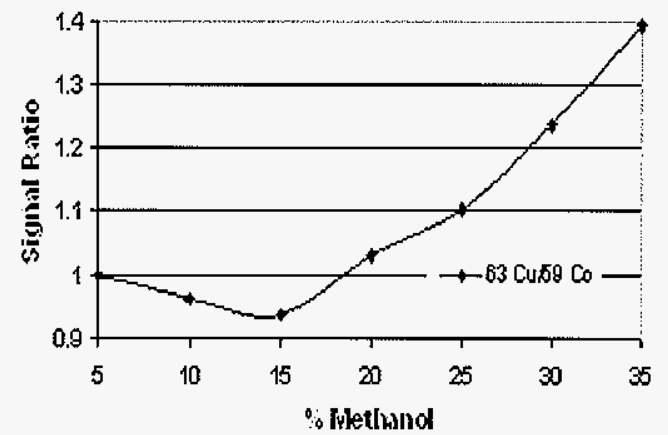

Figure 7. Normalized ion ratios for ${ }^{59} \mathrm{Co} /{ }^{60} \mathrm{Ni}$ in vitamin $\mathrm{B}-12$ (a) ${ }^{59} \mathrm{Co} /{ }^{63} \mathrm{Cu}$ in vitamin $\mathrm{B}-12$ (b),${ }^{63} \mathrm{Cu} /{ }^{59} \mathrm{Co}$ in carbonic anhydrase (c), and ${ }^{63} \mathrm{Cu} /{ }^{59} \mathrm{Co}$ in human blood serum (d) in varying ranges of methanol concentrations. Ion ratios are normalized to show deviation from ratio in $5 \%$ methanol. 


\title{
SOLVENT REMOVAL AND INTERNAL STANDARDIZATION FOR QUANTIFICATION IN LC-ICP-MS WITH GRADIENT ELUTION
}

\author{
A paper to be submitted to The Journal of Analytical Atomic Spectroscopy
}

Patrick A. Sullivan and R. S. Houk*

\begin{abstract}
The groundwork for coupling gradient liquid chromatography (LC) with inductively coupled plasma mass spectrometry (ICP-MS) is continued. Analyte-internal standard (AIS) pairs that remain approximately constant in simulated methanol gradients were tested in actual gradients. Those that showed the best consistency in simulated gradients $\left({ }^{59} \mathrm{Co} /{ }^{60} \mathrm{Ni}\right.$, ${ }^{208} \mathrm{~Pb} /{ }^{205} \mathrm{Tl}$ ) displayed equal signal ratio consistency in an $8 \%$ to $32 \%$ methanol gradient. High resolution trials were performed in order to remove polyatomic interferences for the AIS pairs whose ratios were unstable in low resolution (deviations above $10 \%$ ). The addition of $\mathrm{N}_{2(\mathrm{~g})}$ is shown to increase the tolerable amount of methanol that can be introduced to the desolvator. As a result ${ }^{75} \mathrm{As}^{+} /{ }^{125} \mathrm{Te}^{+}$signal ratio values remain consistent throughout the entire methanol range studied. Quantification experiments were performed in low resolution using ${ }^{60} \mathrm{Ni}$ as an internal standard, added post-column, to quantify Co in a store bought sample of cyanocobalamin (vitamin B-12). The calculated concentration was determined to be $20 \%$ off the expected value.
\end{abstract}

\section{INTRODUCTION}

LC-ICP-MS is an analytical technique that has gained in popularity over the past few years. This technique utilizes both the separation efficiency of LC, and the element selective detection of ICP-MS. Unfortunately, in the case of reverse phase LC, the organic gradients required to perform effective separations greatly reduce the quantification ability of ICP-MS. 
When organic solvents reach the torch, the plasma is destabilized. Within the organic solvent enriched plasma, ion sensitivities are enhanced and suppressed. This change in sensitivity is not the same for all ions. The most effective way to counter the effects of changing solvent matrices on quantification is the use of isotope dilution. This technique works well for quantification in a gradient due to the fact that isotopes of the same element will react to matrix effects in the same manner. ${ }^{1}$

LC-ICP-MS is often used with isotope dilution in elemental speciation studies, where metal containing biological compounds are separated by LC and quantified using the ICPMS. This allows researchers to determine the chemical species in which a given element is found. In such experiments, isotope dilution is not always the answer to the problems of gradient effects. First, some ions of interest in speciation studies have only one stable isotope, e.g. arsenic, manganese, and cobalt. Another issue that limits isotope dilution for some elements is spectral interferences, stable isotopes of more than one element with similar weight. Second, in the case of reverse phase separations, increasing the organic solvent often increases the amount of polyatomic interferences. These polyatomic species can interfere at $\mathrm{m} / \mathrm{z}$ where atomic interferences do not, and decrease the number of available isotopes for use with this technique. ${ }^{2}$ Because of these issues, a method of quantification that does not rely on isotope dilution would be ideal.

In studies performed by Barnes and Al-Ammar, boron and beryllium were shown to experienced similar signal enhancement and suppression in aqueous matrices that exerted non-spectroscopic effects on the elements of interest $(\mathrm{Na}, \mathrm{K}$, and $\mathrm{Ca}){ }^{3}$ Further studies by this group showed similar results for 13 other elements. They surmised that such signal enhancements were a result of space charge effects within the extracted ion beam. ${ }^{4} \mathrm{Hu}$ studied ion signal enhancement and suppression resulting from organic solvent introduction to the plasma. These studies showed that signal enhancement, and suppression, is dependent on the atomic weight and ionization energy of a given element. ${ }^{5}$ Such elements with similar atomic weight and ionization energy have the potential of being used as analyte-internal standard (AIS) pairs during LC quantification.

In a previous study, the exploration of AIS pairs was taken a step further by utilizing the latest developments in sample introduction. With the use of a desolvator, the amount of 
methanol in samples was increased up to $40 \%$ without extinguishing the plasma. In those studies, several AIS pairs were found whose signal ratios do not change greatly (deviations < $\pm 10 \%$ ) over a methanol concentration range of $5-35 \% .^{6}$ For brevity, such AIS pairs are said to remain consistent in the discussion below.

In the current study, the AIS pairs mentioned above were used in conjunction with reverse phase liquid chromatography in order to quantify metal ions bound to biological samples. The ion pairs were tested for signal ratio consistency in the presence of a linear methanol gradient. Methanol gradients ranging from $8 \%$ to $32 \%$ methanol were sent through a $2 \mathrm{~cm}$ C- 18 column, while standard solutions were added post column. Studies were done in low resolution using the HP4500 ICP-MS and in high resolution using the Element 2. The AIS pairs whose ratios remained consistent in the simulated gradient described in a previous study displayed similar ratio consistency in the actual gradients.

One such pair, ${ }^{59} \mathrm{Co}$ and ${ }^{60} \mathrm{Ni}$, was used to quantify $\mathrm{Co}^{2+}$ ions free in solution, and bound to cyanocobalamin in a sample of vitamin B-12. ${ }^{60} \mathrm{Ni}$ was used as the internal standard and was added continuously post-column. The average calculated concentration of free $\mathrm{Co}^{2+}$ ions was determined to be within $-2 \%$ of the actual value. The concentration of ${ }^{59} \mathrm{Co}$ attached to cyanocobalamin in vitamin B-12 was determined to be $20 \%$ over the expected value.

\section{EXPERIMENTAL}

Solutions. Stock solutions were used to make intermediate solutions that were $4 \mathrm{ppm}$ As, $\mathrm{Co}, \mathrm{Cu}, \mathrm{Fe}, \mathrm{Ni}, \mathrm{P}, \mathrm{Pb}, \mathrm{S}, \mathrm{Te}$, and $\mathrm{Tl}$. Standards ranging from $20 \mathrm{ppb}$ to $120 \mathrm{ppb}$ for varying elements were prepared gravimetrically from the intermediates. All standards added post column were $6 \%$ nitric acid in order to obtain a post column mixing acid concentration similar to those used in a previous study. Additionally, a $6 \%$ nitric acid blank solution was prepared for post column addition. A 4 ppm sample of cyanocobalamin (vitamin B-12) was prepared by dissolving tablets containing $2.00 \mathrm{mg}$ of vitamin B- 12 in $500 \mathrm{ml}$ water. The resulting solution was stored at $10{ }^{\circ} \mathrm{C}$. Solutions ranging from $20 \mathrm{ppb}$ to $240 \mathrm{ppb}$ were 
prepared from the standard just prior to injection. Distilled DI water $\left(18 \mathrm{M} \Omega \mathrm{cm}^{-1}\right.$, Milli-Q purification system, Millipore) was used in all sample preparation.

Mobile phase solutions were prepared using DI water and HPLC grade methanol. Solutions of $32 \%$ and $50 \%$ methanol in water were used in conjunction with DI water in the binary pumping system to produce mobile phase gradients ranging from $8 \%$ to $32 \%$ methanol and $10 \%$ to $50 \%$ methanol, prospectively. This was done to keep the flow rate from a given pump above $0.050 \mathrm{ml} / \mathrm{min}$, the lower limit for the pumping system.

LC Instrumentation. A Varian ProStar HPLC solvent introduction system was utilized in this study to generate the methanol gradients. For all of the trials, an Agilent Technologies $2 \mathrm{~cm}$ fast resolution C-18 column was used. Figure 1 shows a block diagram of the experimental setup. All internal standards were added post column using a Cole-Palmer 74900 series syringe pump. The HPLC and syringe pumps were set at equal flow rates, typically $0.300 \mathrm{ml} / \mathrm{min}$. After mixing with the standard, the column eluent was sent through the Apex-Q desolvation system, at $0.100 \mathrm{ml} / \mathrm{min}$, and into the ICP-MS for detection. The remainder of the sample flow was sent to waste. The desolvation system has been previously described. ${ }^{6}$

Quadrupole Instrumentation. The HP 4500 ICP-MS was used for analysis in low resolution. The desolvator replaced the Babington nebulizer and double pass Scott spray chamber that are commonly found on the instrument. Conditions were optimized daily to maximize $\mathrm{M}^{+}$signal in $1 \%$ nitric acid over the full mass range. Typical operating conditions are shown in Table 1.

Magnetic Sector Instrumentation. For medium and high resolution measurements, the Element2 sector field ICP-MS was utilized. As with the HP4500, the desolvation system replaced the conventional spray chamber and nebulizer. The instrument was tuned daily to optimize $\mathrm{M}^{+}$sensitivity for the entire mass range and all three resolution settings. Table 2 shows the typical operation parameters.

Time Program. To insure reproducibility and identical timing for all trials, the same procedure was followed when starting each analysis. First the column was flushed with the starting mobile phase for ten minutes, and the standard solution is added via the syringe pump. This is done to rinse out the lines from previous trials. During this time the nebulizer 
is removed from the desolvator to limit methanol buildup. After rinsing the column and sample lines, the mass spectrometer program is set to take data for one hour and analysis is initiated. After two minutes, the nebulizer is inserted into the desolvator, and an injection is prepared. Four minutes into the analysis, an injection is performed and the solvent gradient is initiated. For the ratio testing trials, an $8 \%$ to $32 \%$ linear methanol gradient was applied over 30 or 45 minutes. For the vitamin B-12 injections, a $10 \%$ to $40 \%$ linear methanol gradient was used as described by Chassaigne. ${ }^{7}$ No injection was needed for the ratio tests, but the procedure was still followed to insure reliability when subtracting blank trials.

\section{RESULTS AND DISCUSSION}

Gradient Elution: Quadrupole Instrument. Standard solutions containing $20 \mathrm{ppb}$ of both ions in a given pair were added post column while a methanol gradient from $8 \%$ to $32 \%$ over 30 to 45 minutes was sent through the column. The post column standard was set at the same flow rate as the column eluent to insure equal mixing, and for simplicity when performing quantification calculations. As a result, the ion concentration and methanol range is cut in half before reaching the desolvator. This effectively extends the range of methanol concentrations that can be sent into the plasma, and helps to make this method suitable for separations at high methanol concentrations.

Figure 2 (a) and (b) show the results obtained for $\mathrm{Co} / \mathrm{Ni}$, and $\mathrm{Pb} / \mathrm{Tl}$. Both ion pairs showed the most consistency in the simulated trials. The two pairs also show ratio deviations below $10 \%$ when an actual gradient is applied. For ${ }^{59} \mathrm{Co} /{ }^{60} \mathrm{Ni}$, there are some points when the ratio deviation is greater than $10 \%$. These points are few when compared to the overall number of measurements, and are most likely due to random signal fluctuations. Figure 2 (c) and (d) show the results obtained for ${ }^{59} \mathrm{Co} /{ }^{63} \mathrm{Cu}$ and ${ }^{60} \mathrm{Ni} /{ }^{63} \mathrm{Cu}$ respectively. Each pair displays ratio consistency in ways that were not predicted by gradient simulations performed in a previous study. ${ }^{6}$ The ratio of ${ }^{59} \mathrm{Co}$ to ${ }^{63} \mathrm{Cu}$ falls drastically after only $15 \%$ methanol, while the ${ }^{60} \mathrm{Ni}$ to ${ }^{63} \mathrm{Cu}$ ratio increases slowly over the entire trial. This is due to polyatomic interferences for each ion that are more severe in the plasma when methanol is present. In the ${ }^{59} \mathrm{Co} /{ }^{63} \mathrm{Cu}$ trial (Figure $2 \mathrm{c}$ ), the interferences on ${ }^{63} \mathrm{Cu}$ have a greater effect during the first 
5 min of the analysis than those on ${ }^{59} \mathrm{Co}$. Beyond this time, the interferences on ${ }^{59} \mathrm{Co}$ increase, and the ratio becomes consistent at a ratio $30 \%$ below the original ratio. In Figure $2 \mathrm{~d}$, the interferences on ${ }^{63} \mathrm{Cu}$ have a grater effect than those on ${ }^{60} \mathrm{Ni}$ over the entire analysis.

Currently, an important element of interest in elemental speciation is As. In gradient simulation trials, As did not behave like ions of similar atomic weight within a methanol enriched plasma. ${ }^{6}$ Figure 3 shows the data obtained from the actual gradient trials performed in order to find a good AIS pair for this elements. The ${ }^{75} \mathrm{As}$ data (Figure 3a) shows that ${ }^{125} \mathrm{Te}$ changes proportionally to ${ }^{75}$ As through the first fifteen minutes of the analysis. After this time the ratio becomes unstable and deviates greatly from that of the starting conditions. This ratio inconsistency coincides with a drop in ${ }^{125} \mathrm{Te}$ signal and increase in ${ }^{75} \mathrm{As}$ signal (Figure 3b). This is a result of too much methanol passing through the desolvator to the plasma. When high concentrations of organic solvents are nebulized for an extended period of time, the desolvator eventually reaches its limits of efficiency. Once this limit is reached, the amount of methanol droplets reaching the plasma is increased. Above this upper methanol limit, As is affected differently than Te, and the ${ }^{125} \mathrm{Te}$ signal drops off faster than the ${ }^{75}$ As signal. This signal decrease can be corrected for by adding $\mathrm{N}_{2(\mathrm{~g})}$ as will be discussed below.

Gradient Elution: Magnetic Sector Instrument. Trials were next performed in high resolution, to remove the polyatomic interferences produced in the methanol enriched plasma. These interferences lead to poor ratio consistency in the low resolution trials for $\mathrm{Cu}$ (Figure 4). As Figure 5 shows the signal ratio stability of ${ }^{59} \mathrm{Co} /{ }^{63} \mathrm{Cu}$ and ${ }^{60} \mathrm{Ni} /{ }^{63} \mathrm{Cu}$ are greatly improved in the high resolution trials. $\mathrm{For}{ }^{59} \mathrm{Co} /{ }^{63} \mathrm{Cu}$, the signal ratio stays well within the $10 \%$ region for the length of the analysis. However, the ${ }^{63} \mathrm{Cu} /{ }^{60} \mathrm{Ni}$ signal ratio still has a few points that are above the $10 \%$ consistency region.

The interferences caused by the methanol may also contribute to the inconsistent behavior of ${ }^{75}$ As and ${ }^{125} \mathrm{Te}$ around the upper methanol limit (Figure 6). $\mathrm{N}_{2(\mathrm{~g})}$ was added to the desolvator sample flow path, for all of the high resolution trials. As Figure $7 \mathrm{~b}$ shows, the addition of $\mathrm{N}_{2(\mathrm{~g})}$ eliminates the upper methanol limit previously seen, in low resolution, at $20 \%$ methanol. As a result the signal ratio remains stable throughout the entire analysis (Figure 7a). This means ${ }^{125} \mathrm{Te}$ can be used as an internal standard for ${ }^{75} \mathrm{As}$. The benefits of 
$\mathrm{N}_{2}$ addition are easy to see, but the reason for such benefits is unclear. Similar results have been seen for introduction of dried aerosols to the system.

Quantification of Vitamin B-12. Quantification trials for vitamin B-12 were performed on the HP 4500 quadrupole ICP-MS due to the fact that ${ }^{59} \mathrm{Co} /{ }^{60} \mathrm{Ni}$ signal ratio was consistent in low resolution over a wide range of methanol concentrations. To test the precision of the method over the wide range of methanol concentrations, multiple $20 \mu \mathrm{L}$ injections of a $20 \mathrm{ppb}$ Co solution were injected on the column over the course of an analysis (Figure 8a). Injections were performed every five minutes, in a 35 minute trial. The unretained peaks were detected 45 seconds after injection and were 1.5 minutes wide. A 20ppb Ni solution was continuously added post column, as the internal standard. The concentration of $\mathrm{Co}$ in each peak was calculated using equation $1 .{ }^{8}$ A ratio of the signals obtained during the analysis of $20 \mathrm{ppb} \mathrm{Co}$ and $\mathrm{Ni}$, added continuously, was

$$
\left(\frac{\mathrm{Co}}{\mathrm{Ni}}\right)_{\exp } \frac{1}{f_{\text {corr }}}=\left(\frac{\mathrm{Co}}{\mathrm{Ni}}\right)_{\text {atomic }}
$$

compared to the ratio of $\mathrm{Co}$ and $\mathrm{Ni}$ atoms sent to the ICP over a designated time (Figure 8b). From this comparison, a correction factor is determined to account for ionization efficiency, mass bias, and isotopic abundance. This factor is then used to compare the signal ratio of the $\mathrm{Ni}$ standard and Co peak to the atomic ratio. From the atomic ratio, the Co concentration can be determined. ${ }^{8}$ Table 3 shows the Co concentrations calculated for the seven peaks in Figure 8a.

Equation 1 was also used to quantify the Co attached to cyanocobalamin in a vitamin B-12 sample. $20 \mu \mathrm{L}$ of a $5.22 \mathrm{ppb}$ Co sample (120 ppb vitamin B-12) was injected onto the column, and eluted using a $10 \%$ to $40 \%$ linear methanol gradient (Figure 9). Ni was again used as the continuous internal standard. At a flow rate of $0.150 \mathrm{ml} / \mathrm{min}$, the cyanocobalamin elutes from the column at $\sim 25$ minutes (Figure 9a). The calculated concentration of the 20 $\mu \mathrm{L}$ injection was $2.83 \mathrm{ppb}$ Co. The low calculated value is due to the fact that the long elution time puts the Co peak into the plasma near the upper methanol limit. At this point even the best AIS pairs struggle with ratio destabilization. To mitigate this problem, the flow rate was increased to $0.300 \mathrm{ml} / \mathrm{min}$. The vitamin B-12 peak then eluted from the column at 8.5 minutes, well under the methanol limit (Figure 9b). The concentration of the $20 \mu \mathrm{L}$ 
injection was then calculated to be $6.26 \mathrm{ppb}$ Co. The high calculated concentration could be due to free cobalt ions in the Vitamin B-12 sample binding to cyanocobalamin. It is also possible that the amount of cyanocobalamin in the store bought sample was higher than specified on the sample container.

\section{CONCLUSIONS}

Ion pairs that displayed signal ratio stability in simulated methanol gradients were tested in actual gradients. Those that showed the best stability in simulated gradients $\left({ }^{59} \mathrm{Co} /{ }^{60} \mathrm{Ni},{ }^{208} \mathrm{~Pb} /{ }^{205} \mathrm{Tl}\right)$ displayed equal signal ratio stability in an $8 \%$ to $32 \%$ methanol gradient. High resolution trials were performed in order to remove polyatomic interferences for the isotopes pairs whose ratios were unstable in low resolution (deviations above $10 \%$ ). The addition of $\mathrm{N}_{2(\mathrm{~g})}$ has been shown to increase the tolerable amount of methanol that can be introduced to the desolvator. As a result ${ }^{75} \mathrm{As}$ and ${ }^{125} \mathrm{Te}$ signal ratio values remain stable throughout the entire methanol range studied. Quantification experiments were performed in low resolution using ${ }^{60} \mathrm{Ni}$ as an internal standard, added post column, to quantify ${ }^{59} \mathrm{Co}$ ions found in a standard sample of cyanocobalamin (vitamin B-12). The calculated concentration was determined to be $20 \%$ off the expected value. Given the stability of the signal ratios, and the possibility for quantification, the method used has great potential to simplify speciation experimentation, and solve the problems that result from coupling reverse phase LC to ICPMS.

\section{ACKNOWLEDGEMENTS}

This study is supported by Ames Laboratory US Department of Energy, the Chemical and Biological Sciences Program, Office of Basic Energy Science, and the ISU Chemistry Department. The Apex-Q desolvation system is on loan from Elemental Scientific Inc. in Omaha, Nebraska. ESI also donated the use of their Element 2 for all of the high resolution experiments. Dan Wiederin of ESI also offered much assistance in the set up and 
development of techniques involving the Apex-Q. Varian provided the HPLC instrumentation, and Hewlett Packard donated the HP 4500 ICP-MS.

\section{REFERENCES}

1. P. Rodríguez-González, J. M. Marchante-Gayón, J. I. G. Alonso, and A. SanzMedel, Spectrochim. Acta Part B 60,151 (2005)

2. R.S. Houk, Handbook of Elemental Speciation 5.7, 379 (2003)

3. A. S. Al-Ammar, E. Reitznerová, and R. M. Barnes, Spectrochim. Acta Part B 54, 1813 (1999)

4. A. S. Al-Ammar, R. K. Gupta, and R. M. Barnes, Spectrochim. Acta Part B 54, 1849 (1999)

5. Z. Hu, S. Hu, S. Gao, Y. Liu, and S. Lin, Spectrochim. Acta Part B 59, $1463 \quad$ (2004)

6. P. Sullivan and R.S. Houk, J. Anal. Atomic Spectro. Pending.

7. H. Chassaigne and J Szpunar, Analusis Magazine 26, 48 (1998)

8. M. Wind, H. Wechst, and W. D. Lehmann, Anal. Chem. 73, 3006 (2001) 
Table 1. ICP-MS operating parameters.

Rf power

Outer gas flow rate

Carrier gas flow rate

Makeup gas flow rate

Sample uptake rate

Sampling depth

Points per mass

Acquisition time per mass

Acquisition time per sample
$1200 \mathrm{~W}$

$16 \mathrm{~L} / \mathrm{min}$

$0.75 \mathrm{~L} / \mathrm{min}$

$0.25 \mathrm{~L} / \mathrm{min}$

$100 \mu \mathrm{L} / \mathrm{min}$

$7.00 \mathrm{~mm}$

3

$0.3 \mathrm{~s}$

$30-120 s$ 
Table 2. Element2 operating parameters.

\begin{tabular}{ll}
\hline & $1475 \mathrm{~W}$ \\
Rf power & $16.04 \mathrm{~L} / \mathrm{min}$ \\
Plasma gas flow rate & $0.736 \mathrm{~L} / \mathrm{min}$ \\
Carrier gas flow rate & $0.279 \mathrm{~L} / \mathrm{min}$ \\
Makeup gas flow rate & $100 \mu \mathrm{L} / \mathrm{min}$ \\
Sample uptake rate & $5.20 \mathrm{~mm}$ \\
Sampling depth & 20 \\
Points per mass & 1.04 hours \\
Acquisition time per sample & \\
\hline
\end{tabular}


Table 3. Accuracy of Co quantification in a methanol gradient.

\begin{tabular}{lccc}
\hline & Actual [Co] & Calculated [Co] & $\frac{\% \text { Error }}{20.5 \mathrm{ppb}}$ \\
Peak 1 & $20 \mathrm{ppb}$ & $18.6 \mathrm{ppb}$ & $+2.50 \%$ \\
Peak 2 & $20 \mathrm{ppb}$ & $17.6 \mathrm{ppb}$ & $-7 \%$ \\
Peak 3 & $20 \mathrm{ppb}$ & $18.6 \mathrm{ppb}$ & $-12 \%$ \\
Peak 4 & $20 \mathrm{ppb}$ & $20.2 \mathrm{ppb}$ & $-7 \%$ \\
Peak 5 & $20 \mathrm{ppb}$ & $20.2 \mathrm{ppb}$ & $+1 \%$ \\
Peak6 & $20 \mathrm{ppb}$ & $21.6 \mathrm{ppb}$ & $+1 \%$ \\
Peak 7 & $20 \mathrm{ppb}$ & $19.6 \mathrm{ppb}$ & $-2 \%$ \\
Average & $20 \mathrm{ppb}$ & & \\
\hline
\end{tabular}




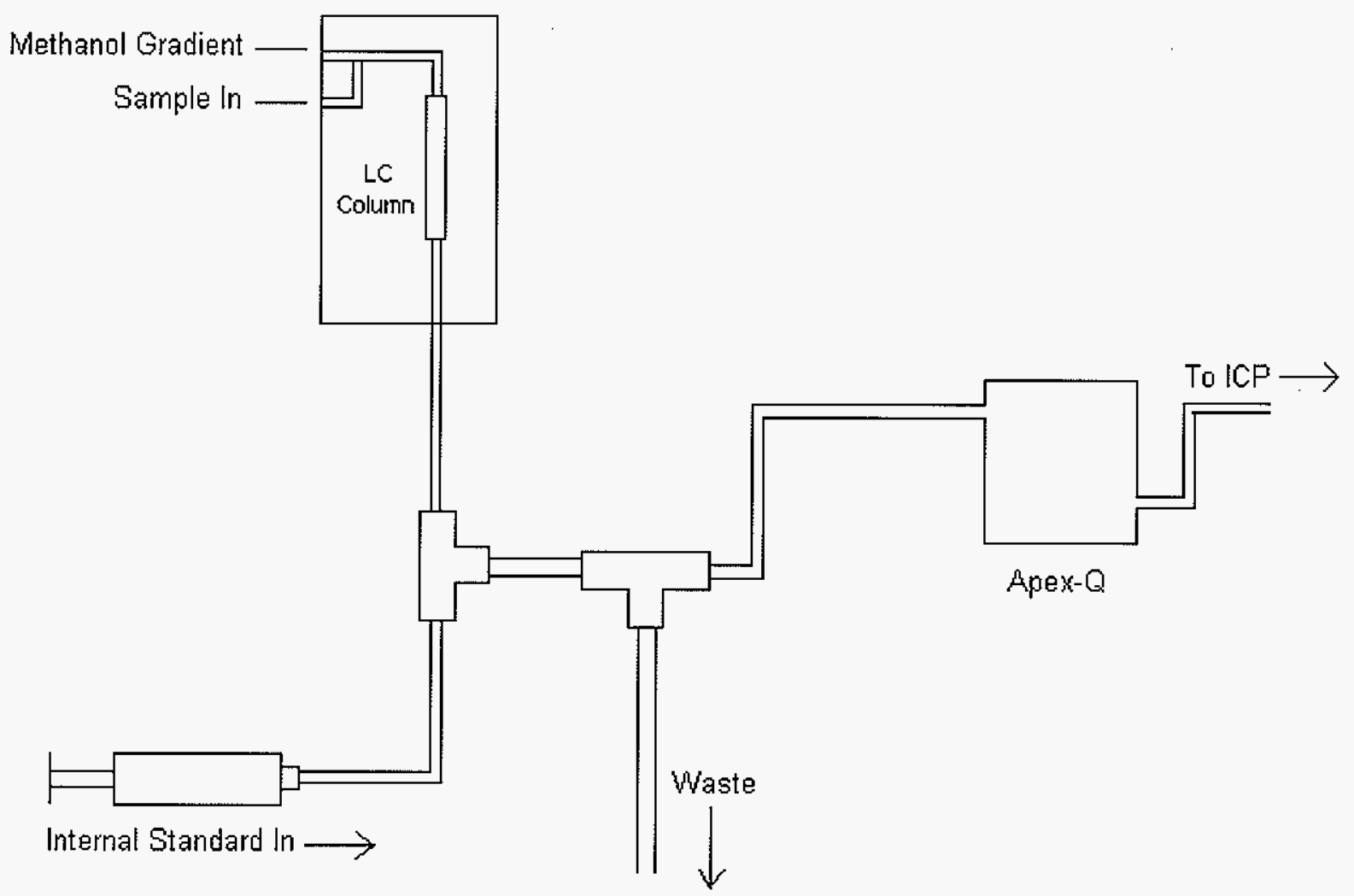

Figure 1. Block diagram of LC-ICP-MS experimental setup. 
(a)

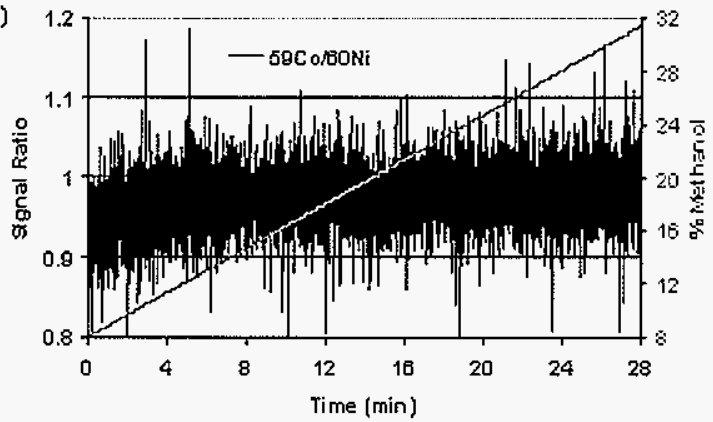

(c)

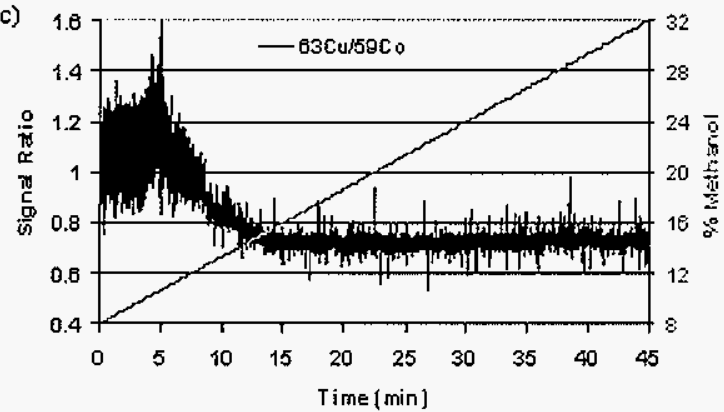

(b)

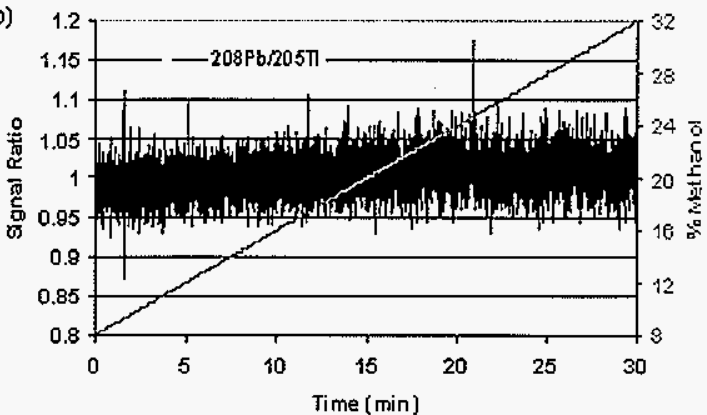

(d)

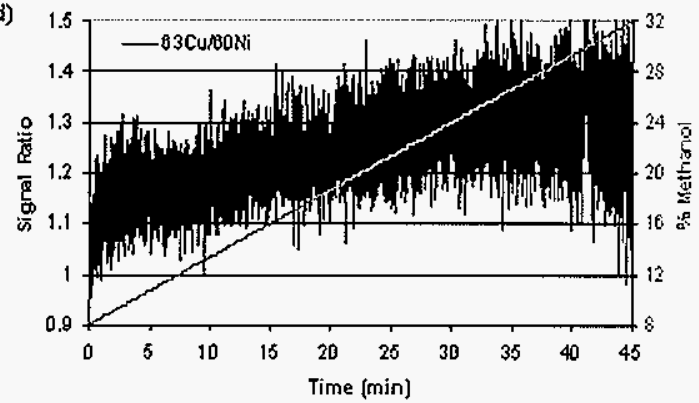

Figure 2. Time resolved quadrupole (low resolution) analysis of (a) ${ }^{59} \mathrm{Co} /{ }^{60} \mathrm{Ni}$, (b) ${ }^{208} \mathrm{~Pb} /{ }^{205} \mathrm{Tl}$, (c) ${ }^{63} \mathrm{Cu} /{ }^{59} \mathrm{Co}$, and (d) ${ }^{63} \mathrm{Cu} /{ }^{60} \mathrm{Ni}$ signal ratios in an $8 \%$ to $32 \%$ methanol gradient. The signal ratios are normalized to show deviations for the initial gradient conditions. 

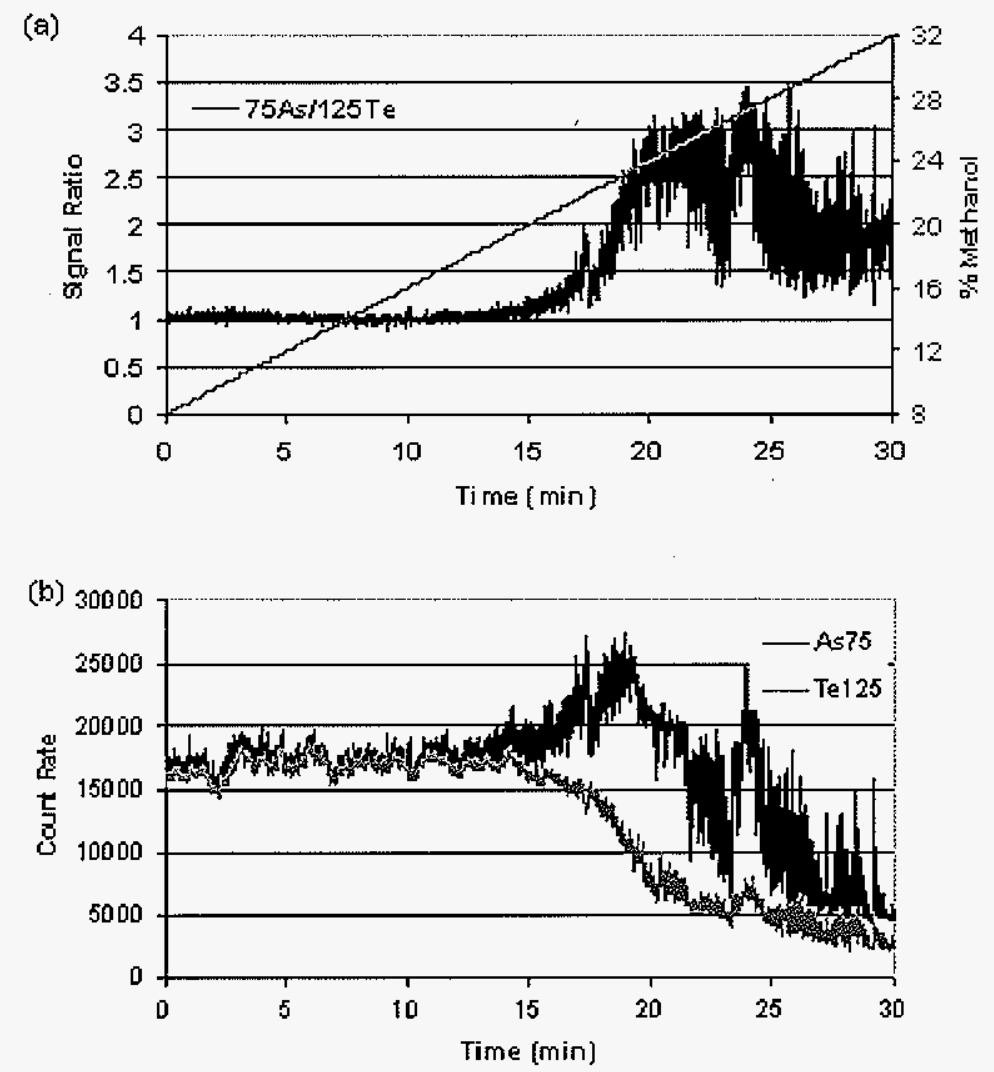

Figure 3. Time resolved quadrupole (low resolution) analysis of (a) ${ }^{75} \mathrm{As} /{ }^{125} \mathrm{Te}$ signal ratio in an $8 \%$ to $32 \%$ methanol gradient, and (b) the chromatograms of their intensities. The signal ratios are normalized to show deviations for the initial gradient conditions. 


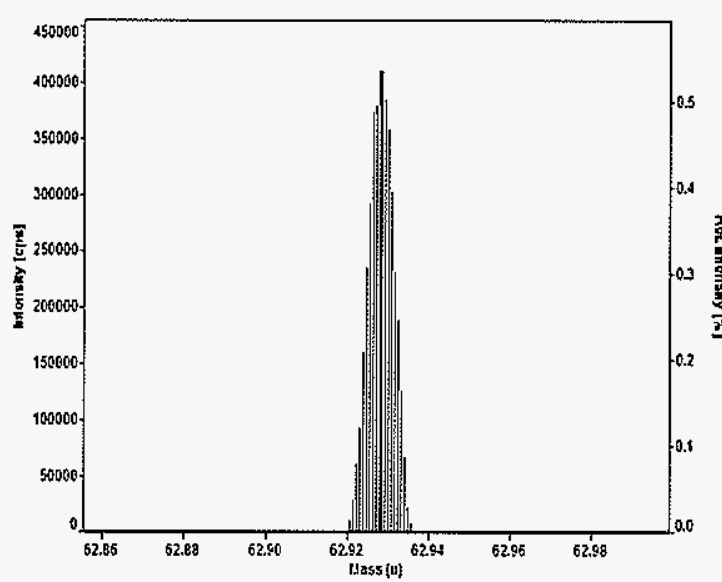

(c)

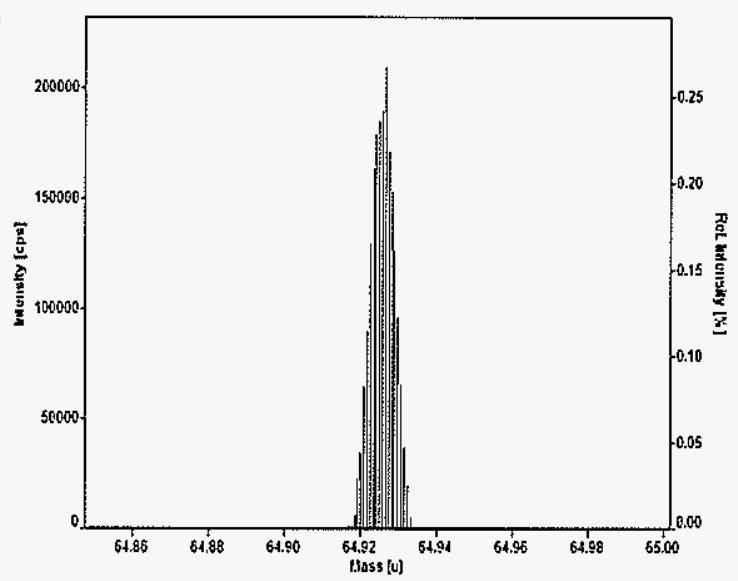

(b)

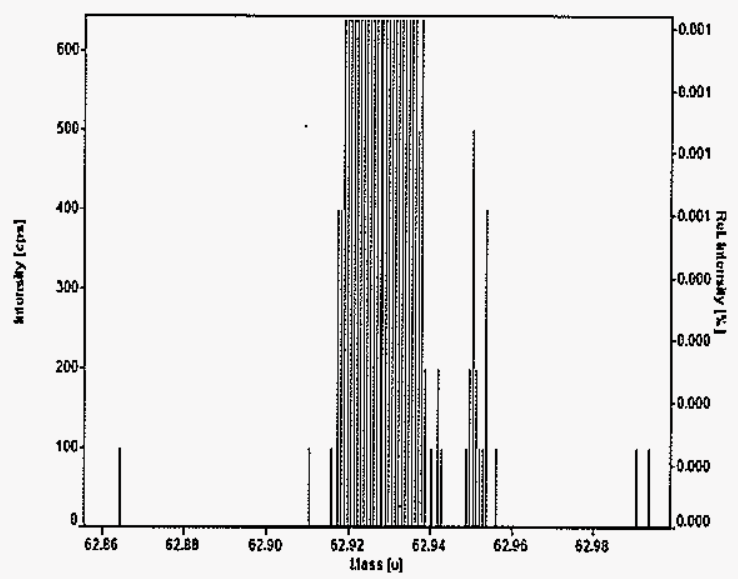

(d)

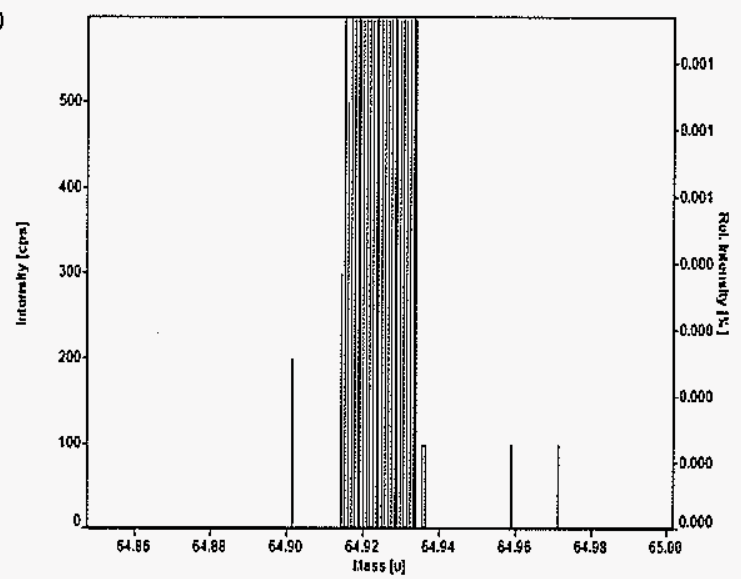

Figure 4. Magnetic sector (medium resolution) mass spectrum showing interferences for ${ }^{63} \mathrm{Cu}^{+}$(a) and (b), and the lack of interferences for ${ }^{65} \mathrm{Cu}^{+}$(c) and (d) in a $16 \%$ methanol solution. $\mathrm{N}_{2(\mathrm{~g})}$ was added to the desolvator to prevent solvent overload. 
(a)

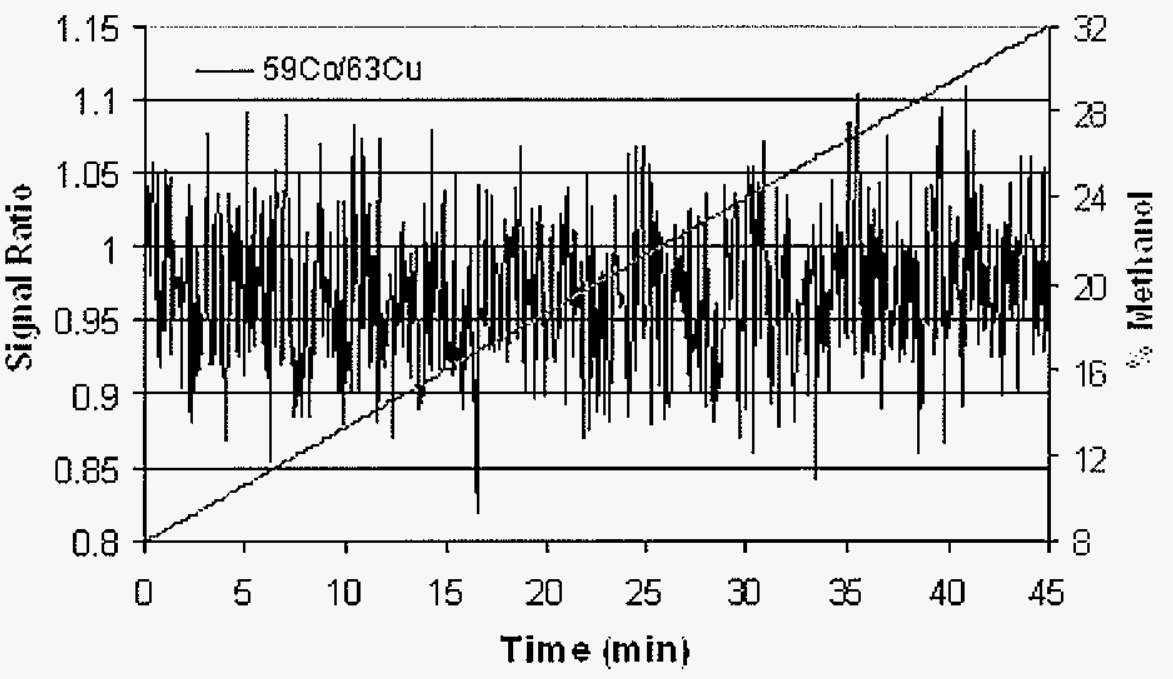

(b)

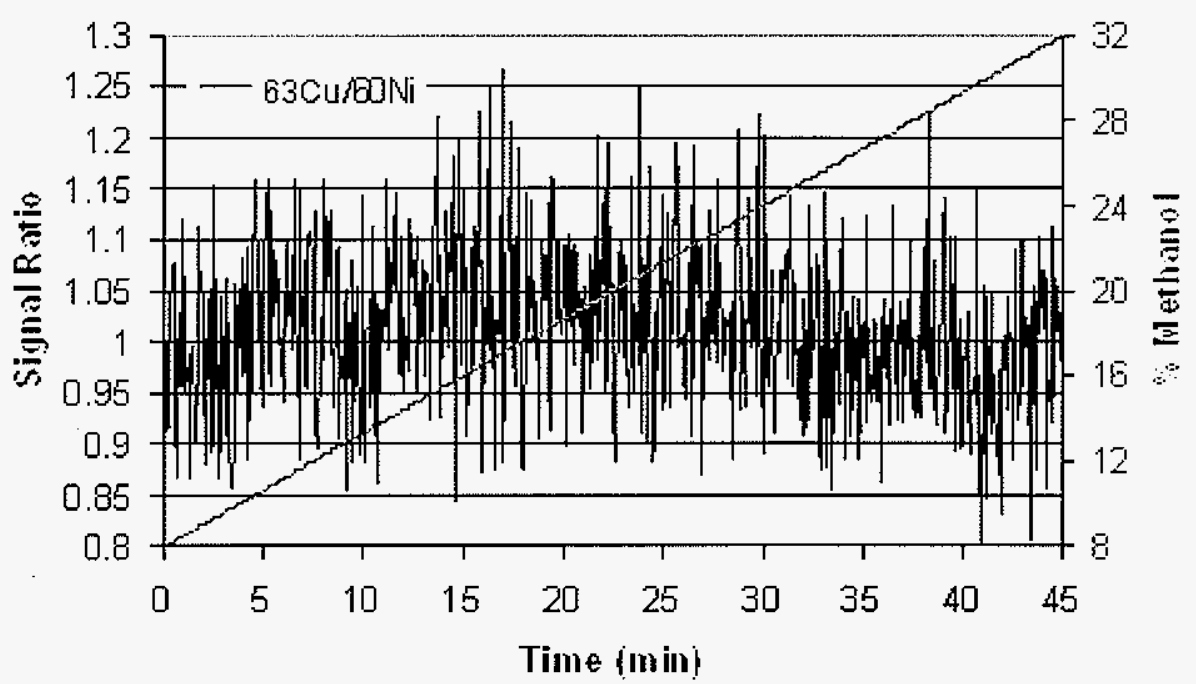

Figure 5. Time resolved magnetic sector (high resolution) analysis of (a) ${ }^{59} \mathrm{Co} /{ }^{63} \mathrm{Cu}$ and (b) ${ }^{63} \mathrm{Cu} /{ }^{60} \mathrm{Ni}$ signal ratios in an $8 \%$ to $32 \%$ methanol gradient. The signal ratios are normalized to show deviations for the initial gradient conditions. 
(a)

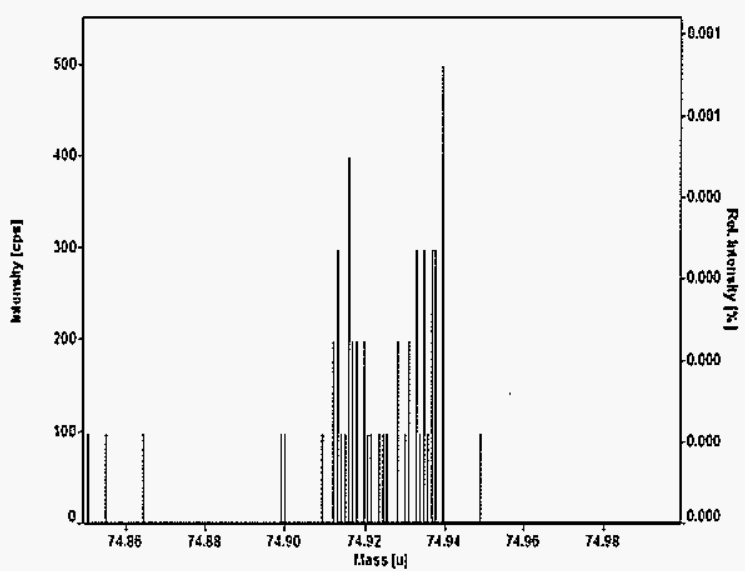

(c)

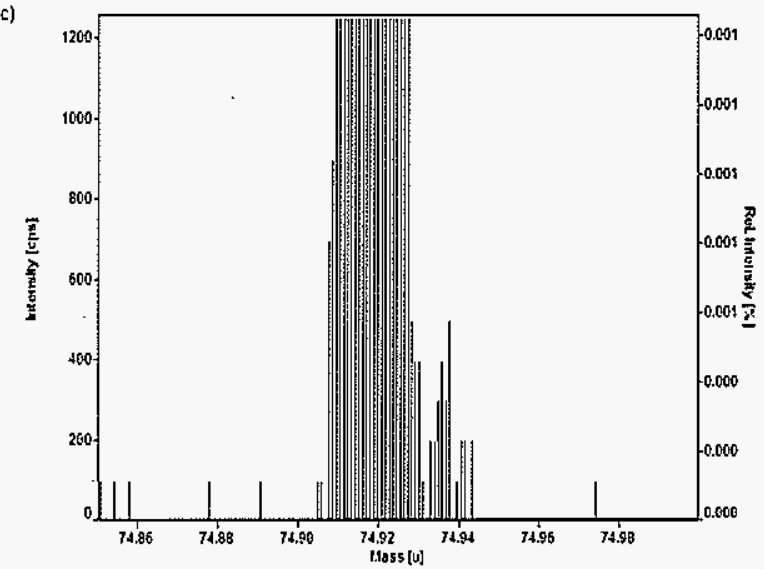

(b)

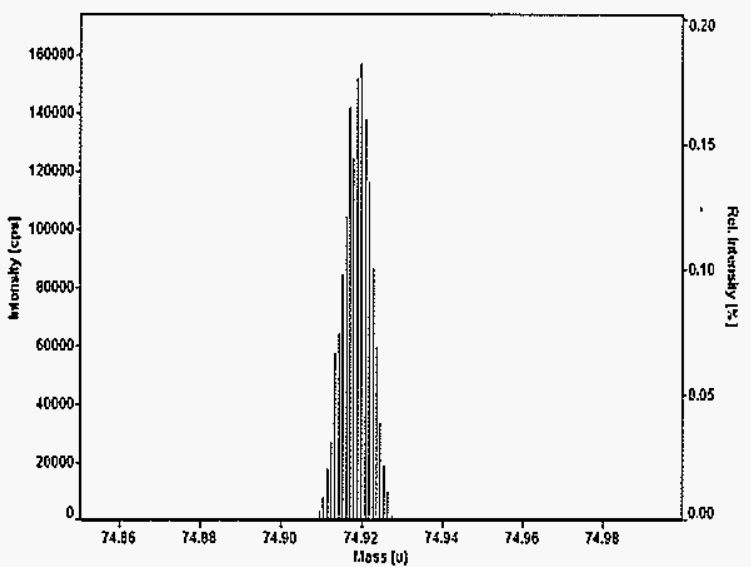

(d)

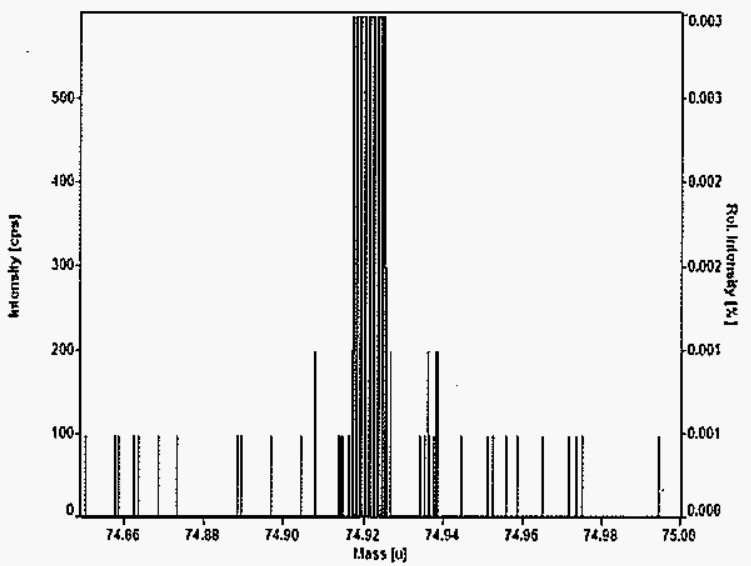

Figure 6. Magnetic sector (medium resolution) mass spectrum showing interferences for $\mathrm{a}^{75} \mathrm{As}^{+}$blank (a), and a 4ppb solution (b) and (c) in a $16 \%$ methanol solution. (d) High resolution spectrum of the same As and methanol solutions. $\mathrm{N}_{2(\mathrm{~g})}$ was added to the desolvator to prevent solvent overload. 
(a)

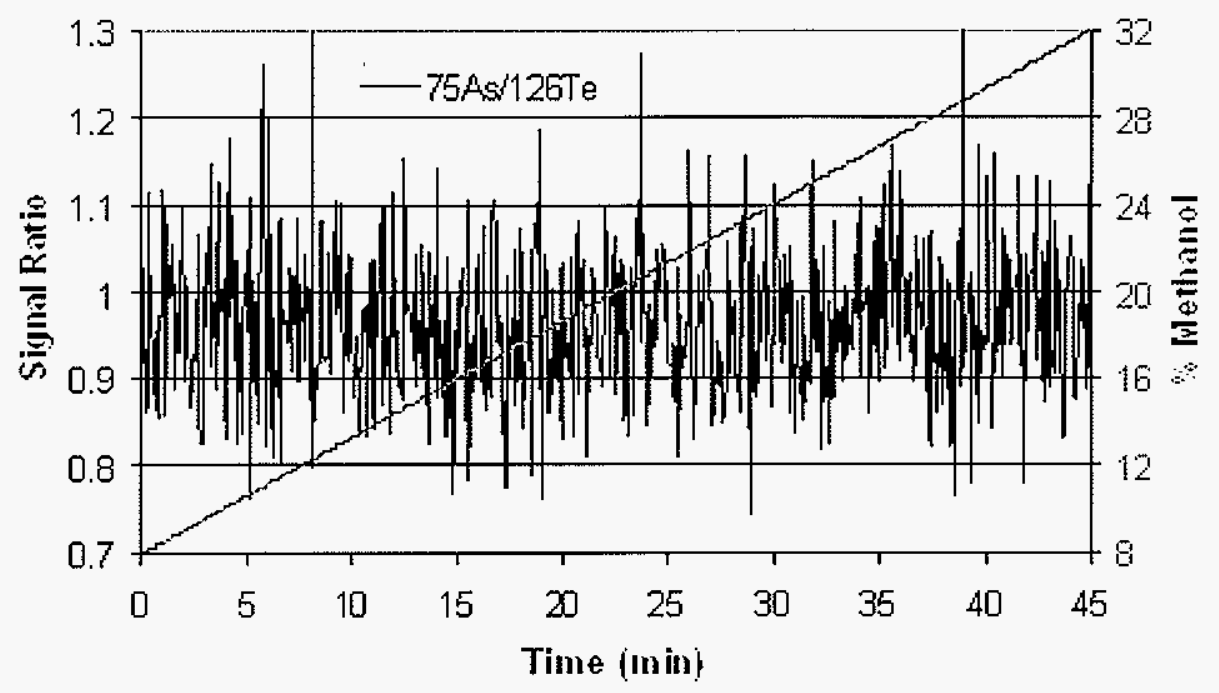

(b)

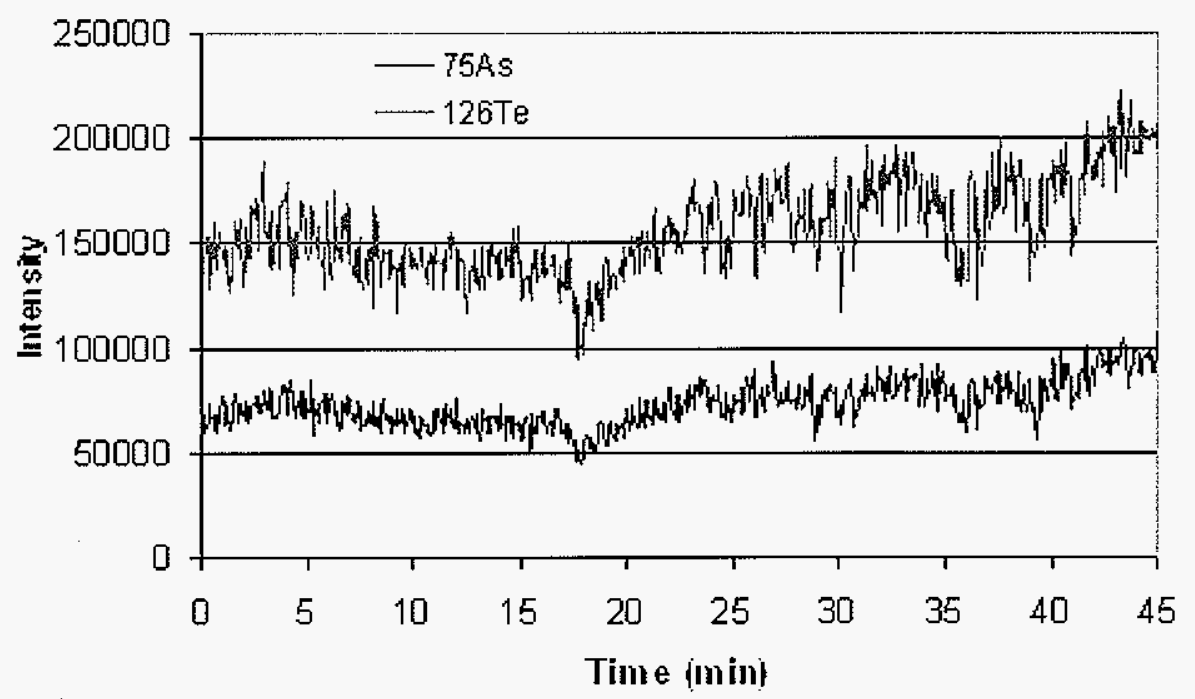

Figure 7. Time resolved magnetic sector (high resolution) analysis of (a) ${ }^{75} \mathrm{As} /{ }^{126} \mathrm{Te}$ signal ratios in an $8 \%$ to $32 \%$ methanol gradient, and the chromatograms of their intensities (b). The signal ratio is normalized to show deviations for the initial gradient conditions. $\mathrm{N}_{2(\mathrm{~g})}$ is added to improve solvent removal. 
(a)

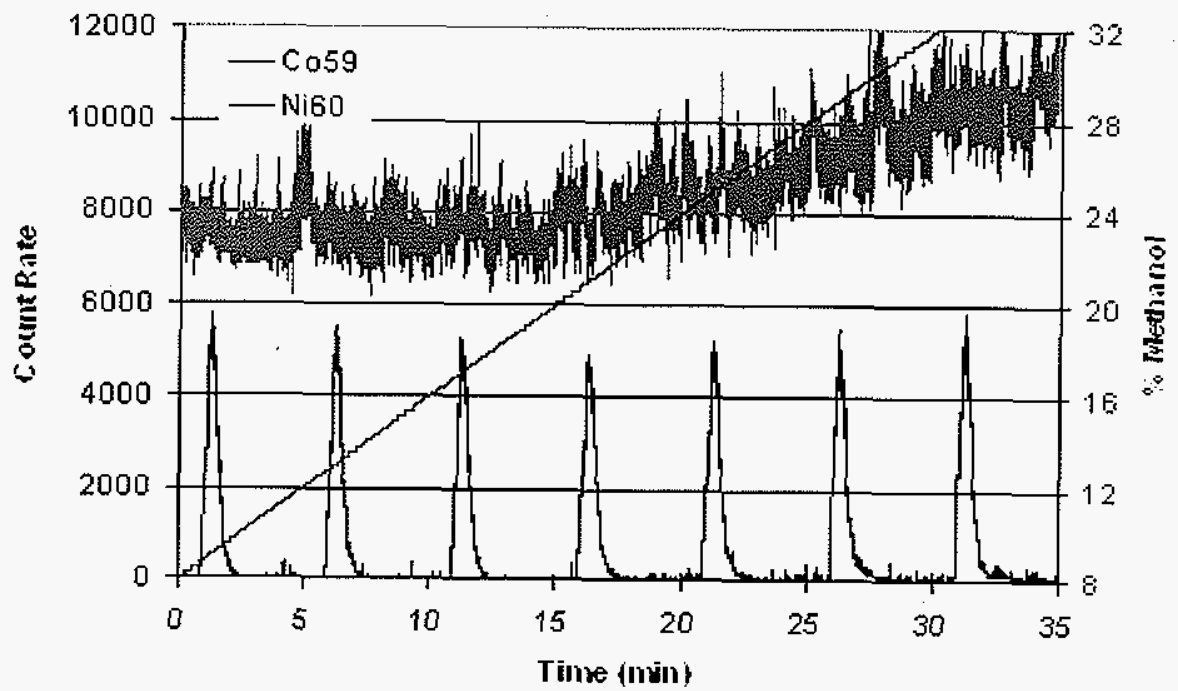

(b)

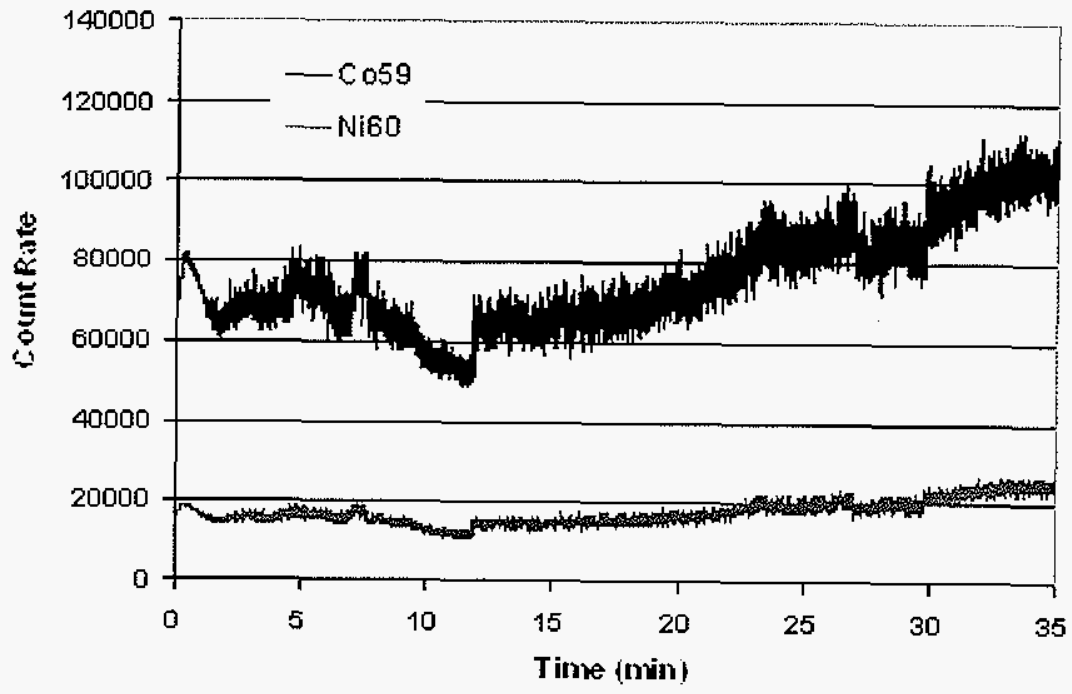

Figure 8. Time resolved quadrupole (low resolution) analysis of (a) a chromatogram of multiple Co injections during an $8 \%$ to $32 \%$ linear methanol gradient, over 30 minutes, with a flow rate of $0.300 \mathrm{ml} / \mathrm{min}$. ${ }^{60} \mathrm{Ni}$ is continuously added post column for use as the internal standard. (b) Continuous standard addition of $20 \mathrm{ppb}$ Co and Ni, over the same linear gradient, for use in quantification. 
(a)

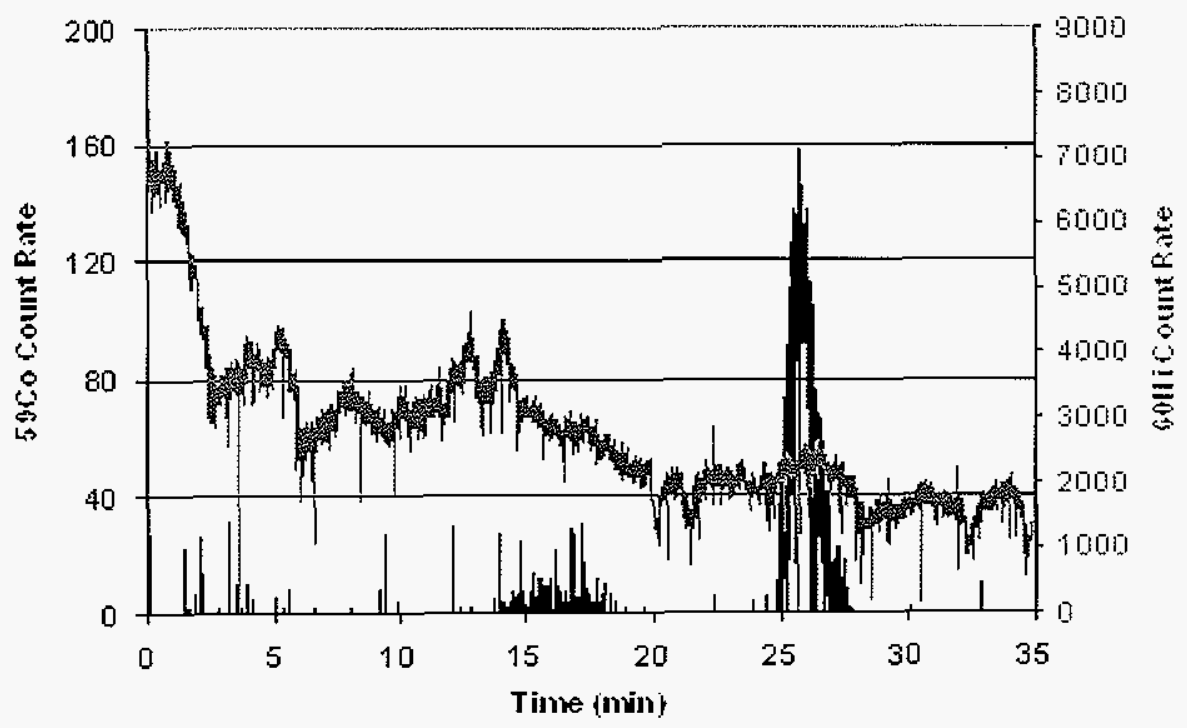

(b)

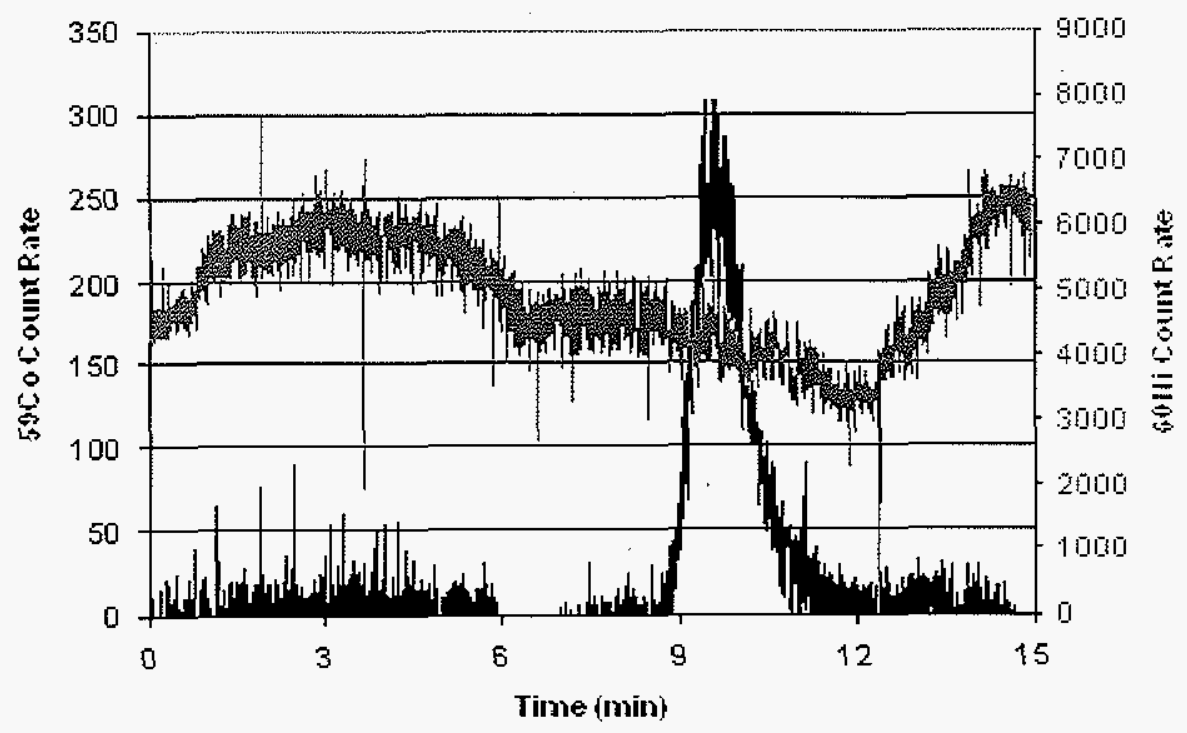

Figure 9. Time resolved quadrupole (low resolution) analysis of a chromatogram of ${ }^{59} \mathrm{Co}^{+}$from vitamin B-12 using a $10 \%$ to $40 \%$ linear methanol gradient over 30 minute with a flow rate of (a) $0.150 \mathrm{ml} / \mathrm{min}$ and (b) $0.300 \mathrm{ml} / \mathrm{min}$. ${ }^{60} \mathrm{Ni}$ is continuously added post column for use as the internal standard. 


\section{GENERAL CONCLUSION}

In this preliminary study, the feasibility of coupling LC to ICP-MS through a desolvation system was explored. The desolvator in question was shown to efficiently remove organic solvents from single samples ranging up to $35 \%$ methanol in water. With continuous organic solvent addition, the solvent limit dropped to $15 \%$ methanol in water. This could be corrected by adding $\mathrm{N}_{2}$ gas to the sample flow path. The desolvator was shown to add little band broadening to samples nebulized into the system. Most sample broadening took place in the lines connecting the column to the desolvator. To insure low broadening and efficient separations, the flow path between the LC and desolvation system should be kept to a minimum.

In simulated and actual gradient elution, analyte-internal standard (AIS) pairs were found whose ratios remained consistent over a wide range of methanol concentrations. These pairs exhibited ratio deviations less than $\pm 10 \%$. Most analyses were performed in low resolution using a quadrupole ICP-MS instrument. For some isotopes, high resolution measurements were required to remove polyatomic interferences formed in a methanolenriched plasma. These analyses were performed using a magnetic sector ICP-MS device.

Quantification was performed in low resolution using one AIS pair $\left({ }^{59} \mathrm{Co}\right.$ and $\left.{ }^{60} \mathrm{Ni}\right)$. Using multiple injections of a known standard, the accuracy of the method was studied. The average error was calculated to be $-2 \%$ over a methanol concentration gradient of $8 \%-32 \%$ in water. When injecting a store-bought sample of vitamin B-12, the Co concentration was calculated to be $20 \%$ over the expected value.

Although this study did not solve all of the problems that arise when coupling LC with ICP-MS, vast improvements are evident. Through post-column solvent removal, greater amounts of organic solvents can be utilized. This will improve both the duration and efficiency of analyte separations performed. This greater solvent load does not adversely affect the quantification ability of the method. With further study, this method has the potential to be a good alternative to isotope dilution when quantification is desired for $\mathrm{LC}$ separations. 